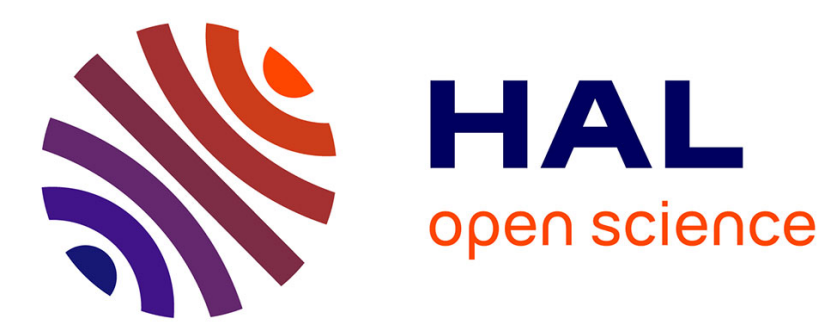

\title{
Search for active lava flows with VIRTIS on Venus Express
}

\author{
N. Mueller, S. Smrekar, J. Helbert, E. Stofan, G. Piccioni, P. Drossart
}

\section{To cite this version:}

N. Mueller, S. Smrekar, J. Helbert, E. Stofan, G. Piccioni, et al.. Search for active lava flows with VIRTIS on Venus Express. Journal of Geophysical Research. Planets, 2017, 122 (5), pp.1021-1045. 10.1002/2016JE005211 . obspm-02190719

\section{HAL Id: obspm-02190719 https://hal-obspm.ccsd.cnrs.fr/obspm-02190719}

Submitted on 31 Dec 2021

HAL is a multi-disciplinary open access archive for the deposit and dissemination of scientific research documents, whether they are published or not. The documents may come from teaching and research institutions in France or abroad, or from public or private research centers.
L'archive ouverte pluridisciplinaire HAL, est destinée au dépôt et à la diffusion de documents scientifiques de niveau recherche, publiés ou non, émanant des établissements d'enseignement et de recherche français ou étrangers, des laboratoires publics ou privés. 


\section{Journal of Geophysical Research: Planets}

\section{RESEARCH ARTICLE \\ Search for active lava flows with VIRTIS on Venus Express}

10.1002/2016JE005211

\begin{abstract}
Key Points:
- A search of VIRTIS data resulted in no detection of thermal emission of active lava flows on Venus

- A thermal and atmospheric model estimates size and eruption rate of detectable active lava flows

- Plausible assumptions on eruption volume and duration result in an upper bound of volcanic activity
\end{abstract}

Correspondence to:

N. T. Mueller,

nils.muller@jpl.nasa.gov

\section{Citation:}

Mueller, N. T., S. Smrekar, J. Helbert, E. Stofan, G. Piccioni, and P. Drossart (2017), Search for active lava flows with VIRTIS on Venus Express, J. Geophys. Res. Planets, 122, 1021-1045, doi:10.1002/2016JE005211.

Received 9 NOV 2016 Accepted 5 MAY 2017 Accepted article online 10 MAY 2017 Published online 27 MAY 2017

@2017. American Geophysical Union. All Rights Reserved.

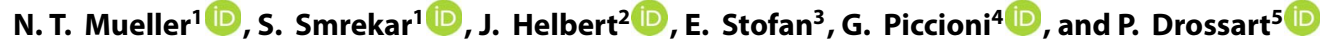 \\ ${ }^{1}$ Jet Propulsion Laboratory, California Institute of Technology, Pasadena, California, USA, ${ }^{2}$ DLR-Institute of Planetary \\ Research, Berlin, Germany, ${ }^{3}$ Johns Hopkins University Applied Physics Laboratory, Laurel, Maryland, USA, ${ }^{4}$ INAF-IAPS, \\ Rome, Italy, ${ }^{5}$ LESIA, Observatoire de Paris, Paris, France
}

\begin{abstract}
The Visible Infrared Thermal Imaging Spectrometer (VIRTIS) instrument on Venus Express observed thermal emission from the surface of Venus at $1 \mu \mathrm{m}$ wavelength and thus would have detected sufficiently bright incandescent lava flows. No eruptions were detected in the observations between April 2006 and October 2008, covering an area equivalent to 7 times the planets surface on separate days. Models of the cooling of lava flows on Earth are adapted to Venus ambient conditions to predict thermal emission based on effusion rate. Taking into account the blurring of surface thermal emission by the atmosphere, the VIRTIS images would detect eruptions with effusion rates above 500 to $1000 \mathrm{~m}^{3} / \mathrm{s}$. On Earth such eruptions occur but are rare. Based on an eruption rate and duration distribution fitted to historical data of three terrestrial volcanos, we estimate that only a few percent of all eruptions are detectable. With these assumptions the VIRTIS data can constrain the rate of effusive volcanism on Venus to be less than about $300 \mathrm{~km}^{3} / \mathrm{yr}$, at least an order of magnitude higher than existing constraints. There remains a large uncertainty because of unknown properties of lava flows on Venus. Resolving flows in radar imaging and their thickness in altimetry might help to better constrain these properties. While VIRTIS data do not represent a significant constraint on volcanism, an optimized instrument with a 20 times better signal-to-noise ratio would likely be able to detect effusion rates on the order of $50 \mathrm{~m}^{3} / \mathrm{s}$.
\end{abstract}

Plain Language Summary Venus has a thick, cloudy atmosphere that shields its surface from imaging and asteroid impacts. We know from radar imaging that there are many volcanos on Venus, but we do not know how active they are. The spacecraft Venus Express observed the infrared radiation of the hot surface of Venus through the global cloud layer. If there had been an active lava flow, the even higher surface temperature might have been detected in these data. We did not see anything in the data that clearly must have been caused by an active volcanic eruption. We show that only eruptions that produce a comparatively large volume of lava per second would be clearly visible. On Earth such eruptions occur but only a few per thousand years. It is possible that Venus has more volcanic eruptions than Earth, but not so many that we could have expected to find one in our data. We will need better observations to see more typical eruptions and more images to have a good chance of directly observing an eruption on Venus.

\section{Introduction}

The style and rate of geologic activity on a planetary surface provide fundamental information on the evolution of the atmosphere and interior. The resurfacing age of Venus inferred from the crater number is between 300 and 1000 Myr [McKinnon et al., 1997], although a recent study of near-Earth asteroid size frequency distribution suggest a much younger mean age of 50-250 Myr [Bottke et al., 2016], indicating a much higher rate of volcanic resurfacing than previously thought. The small number of craters and apparent dearth of craters modified by volcanism or tectonism has lead to a major debate about the rate of volcanism with time. The distribution of craters cannot be distinguished from a random one [Hauck et al., 1998] and thus can fit both a rapid (episodic) pulse of volcanism that resurfaced the entire planet [Schaber et al., 1992; Strom et al., 1994] and localized volcanism at a steady rate in equilibrium with impacts [Phillips et al., 1992; Phillips and Izenberg, 1995].

The main difference between these models is the current global rate of volcanism, which is an order of magnitude higher than for the equilibrium model compared to the quiescent period of the episodic model. The absolute rates are uncertain due to the unknown thickness of the resurfacing layers; more details are given in section 2.1. Existing radar data [Lorenz, 2015] and indirect evidence for volcanism from the existence 
of sulphuric acid clouds [e.g., Fegley and Prinn, 1989; Hashimoto and Abe, 2005], variability of $\mathrm{SO}_{2}$ [e.g., Esposito, 1984; Marcq et al., 2013], and possibly recent lava flows [Basilevsky, 1993; Smrekar et al., 2010; Bondarenko et al., 2010] do not provide a clear constraint on the current rate of volcanism.

Hashimoto and Imamura [2001] propose to constrain the rate of active volcanism by monitoring the thermal emission of the surface through the near-infrared windows near $1 \mu \mathrm{m}$ [e.g., Allen and Crawford, 1984; Lecacheux et al., 1993]. Scattering in the optically thick, global cloud layer would blur the thermal emission and reduce the maximum intensity, but Hashimoto and Imamura [2001] argue that some plausible eruptions would be detectable.

The Venus Monitoring Camera (VMC) [Markiewicz et al., 2007] on the ESA mission Venus Express [Svedhem et al., 2007] acquired $1 \mu \mathrm{m}$ images of the nightside of Venus from 2006 to 2015. Shalygin et al. [2015] report the observation of several transient bright spots at fixed locations visible through the clouds moving with the superrotating atmosphere. They show that the brightness of these spots is consistent with active lava flows or lakes that are not unusually large compared to eruptions on Earth. Shalygin et al. [2015] discuss several possible explanations for the transient bright spots and conclude that active volcanism is most likely. Shalygin et al. [2015] give no estimate on the rate of volcanism that is consistent with these putative eruptions in the VMC data set.

The infrared mapping channel of the Visible and Infrared Thermal Imaging Spectrometer (VIRTIS-M IR) has imaged the thermal emission of Venus with 432 spectral bands between 1 and $5 \mu \mathrm{m}$ from April 2006 to September 2008. VIRTIS-M IR has acquired approximately 1300 images with sufficient exposure time to observe surface thermal emission. It observed an area equal to approximately 7 times the planetary surface on different days, but did not observe any clear signature of an active lava flow. Due to the Venus Express orbit only the southern hemisphere has been contiguously mapped, thus the locations with putative volcanic activity reported by Shalygin et al. [2015] and Bondarenko et al. [2010] are not covered.

In order to interpret the nonobservation of active lava flows in VIRTIS images we develop a model to predict expected numbers of detections, including estimates of the visibility of lava flows and frequency of detectable eruptions. In order to estimate the area integrated brightness of lava flows, we adjust typical surface temperature distributions of several types of basaltic lava flows from the work of Wright et al. [2011] to Venus conditions and constrain the radiating area from the cooling timescale and assumed values for effusion rate and flow thickness.

The effusion rate and eruption volume distributions of Venus volcanism are not known, but the data of Malin [1980] and Wadge [1981] of the eruptions on Hawaii between 1840 and 1980 sample such distributions for the closest terrestrial analogue to the Venusian hot spot volcanos. This gives the probability that an eruption is detectable and the expected frequency of all eruptions as function of global rate of volcanism. Together with the constraint on excess thermal emission placed by VIRTIS data, these models provide an upper bound on the rate of Hawaii-like volcanism on Venus and allow us to estimate what improvements to instrumentation and monitoring are necessary to distinguish between the resurfacing hypotheses.

\section{Background}

\subsection{Estimates and Constraints for the Rate of Volcanism}

The episodic resurfacing [Schaber et al., 1992; Strom et al., 1994] implies initial rates on the order of at least $45 \mathrm{~km}^{3} / \mathrm{yr}$ initially [Stofan et al., 2005], with subsequent rates on the order of $0.01 \mathrm{~km}^{3} / \mathrm{yr}$ [Schaber et al., 1992]. The equilibrium scenario predicts volcanic resurfacing rates of $1 \mathrm{~km}^{3} / \mathrm{yr}$ [Phillips et al., 1992]. As these two scenarios assume the minimum thickness of lava required to completely bury craters and impact basins, the volume rates may be underestimates. Romeo and Turcotte [2010] consider the resurfacing as emplacement of cones with shallow slopes similar to those found on the surface of Venus and find recent volume rates of $2 \mathrm{~km}^{3} / \mathrm{yr}$ for the episodic and $40 \mathrm{~km}^{3} / \mathrm{yr}$ for the equilibrium resurfacing models. The two models may not be mutually exclusive. Ivanov and Head [2015] conclude, based on global geological mapping [/vanov and Head, 2011] and stratigraphy of volcanic units [/vanov and Head, 2013], that the style of volcanism changed over time, from pervasive eruptions creating the vast featureless regional plains and erasing the crater record, to more localized volcanism creating lobate plains more in equilibrium with the creation of new craters. Ivanov and Head [2013] use the volume of the lobate plain units to estimate the recent rate of volcanism to be 0.3 to $0.4 \mathrm{~km}^{3} / \mathrm{yr}$. 
Other considerations are of relevance for the rate of volcanism. Venus lacks a system of plate tectonics comparable to Earth [e.g., Kaula and Phillips, 1981] and must have a thick lithosphere to support its range of topography [Pettengill et al., 1980]. If Venus has similar radiogenic heat production rate as Earth, the heat would require either a transport mechanism other than plate tectonics and conduction or accumulate in the interior [Turcotte, 1989]. The rate of magmatism required to transport this heat through the lithosphere is on the order of $200 \mathrm{~km}^{3} / \mathrm{yr}$ [Turcotte, 1989]. Fractionation of heat producing elements into the crust may reduce the required rate of magmatism to $90 \mathrm{~km}^{3} / \mathrm{yr}$ [Spohn, 1991]. Armann and Tackley [2012] include the heat budget in a numerical model of mantle dynamics allowing for episodic behavior. They find rates of magmatism on the order of $10^{3} \mathrm{~km}^{3} / \mathrm{yr}$ in $150 \mathrm{Myr}$ long episodes of foundering lithosphere and rates on the order of $50 \mathrm{~km}^{3} / \mathrm{yr}$ in periods of stable lithosphere lasting approximately $0.5 \mathrm{Gyr}$. It is unclear how much of this magmatism contributes to extrusive, directly observable volcanism. The ratio of intrusive to extrusive volcanism is estimated to be 5 to 1 for basaltic crust on Earth [Crisp, 1984], but this might be different for the higher temperature and less mobile lithosphere of Venus.

The abundance and apparent variability of sulphur species in the atmosphere has been linked to active volcanism. If there are carbonate minerals present on the surface of Venus, they would act as a $\mathrm{SO}_{2}$ sink and it would require degassing equivalent to a rate of volcanism of $0.4-10 \mathrm{~km}^{3} / \mathrm{yr}$ to sustain the $\mathrm{H}_{2} \mathrm{SO}_{4}$ cloud layer [Fegley and Prinn, 1989]. As an alternative, Hashimoto and Abe [2005] propose that the $\mathrm{SO}_{2}$ abundance and climate is stabilized through a chemical albedo feedback. The decadal variability of $\mathrm{SO}_{2}$ above the cloud layer has been considered as evidence for active volcanism [Esposito, 1984] but could also be explained by atmospheric dynamics [e.g., Marcq et al., 2013].

Mueller et al. [2008] derive empirical relations to correct the VIRTIS $1.02 \mu \mathrm{m}$ images photometrically and for the varying cloud opacity and topography. A mosaic of the images averaged over time shows some areas where the thermal emission is significantly increased compared to other surfaces of the same elevation. Mueller et al. [2008] find that active volcanism is an unlikely explanation because the anomalies did not change significantly over the course of the 2 years of observations.

Smrekar et al. [2010] find that the increased emissivity in areas reliably mapped by VIRTIS data is mostly located at stratigrapically young lava flows at volcanic edifices in regions interpreted to be locations above mantle plumes (hot spots) similar to the setting of Hawaii on Earth [Smrekar and Phillips, 1991; Smrekar, 1994; Stofan et al., 1995]. The large inferred emissivity difference between the surrounding plains and volcanic flows is interpreted as a result of chemical weathering of the plains as expected from Venus analogue experiments [Fegley and Prinn, 1989; Fegley et al., 1992; Treiman and Allen, 1994; Fegley et al., 1995a, 1995b]. Using the rate of volcanism of the episodic $\left(0.01 \mathrm{~km}^{3} / \mathrm{yr}\right)$ and the equilibrium $\left(1 \mathrm{~km}^{3} / \mathrm{yr}\right)$ resurfacing models and flow thicknesses between 10 and $100 \mathrm{~m}$ Smrekar et al. [2010] estimate a time of emplacement of the flows between $2.5 \mathrm{Myr}$ and 2500 years, with the latter being more consistent with the speed of weathering reactions measured in the laboratory. However, the weathering process is not well understood and therefore the increased emissivity does not constrain the age of the flows and thus not the rate of volcanism.

Lorenz [2015] consider the possibility of detecting the emplacement of new lava flows by comparing Magellan synthetic aperture radar images acquired at different times. Since no such detection has been published, Lorenz [2015] argue that this points toward a rate of volcanism $<1 \mathrm{~km}^{3} / \mathrm{yr}$ if new flows significantly larger than Magellan resolution were detected with $100 \%$ certainty. However, if new flows have similar radar brightness, the detection becomes unlikely. In studies of Magellan radar images, the individual flow lobes making up a flow field usually cannot be identified [e.g., Stofan et al., 2001].

\subsection{Atmospheric Scattering}

Hashimoto and Imamura [2001] model the scattering of photons in the optically thick clouds of Venus and conclude that near-infrared radiation from a surface point source emerges from the top of atmosphere with a Gaussian spatial distribution, which can be expressed as

$$
E_{\mathrm{TOA}}(I)=\frac{E T_{r a}}{2 \pi \sigma_{\mathrm{TOA}}^{2}} \exp \left(-\frac{P^{2}}{2 \sigma_{\mathrm{TOA}}^{2}}\right)
$$

where $E_{\mathrm{TOA}}$ is top of atmosphere radiance, $l$ is the horizontal distance from the point source, $\sigma_{\mathrm{TOA}}$ is the standard deviation of the distribution, $E$ is the total radiance emitted from the point source, and $T_{r a}$ is total atmospheric transmittance. From a cloud model with optical thickness 20 between 50 and 70 km altitude, 


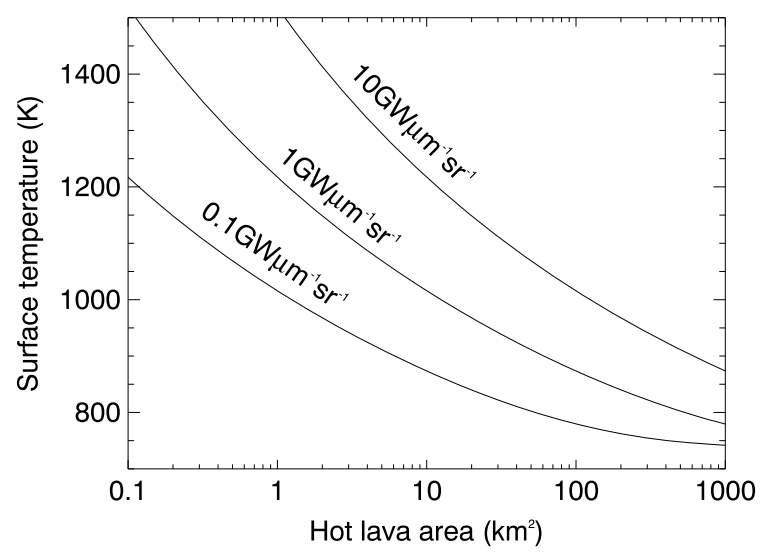

Figure 1. Detection thresholds of $0.1,1$, and $10 \mathrm{GW}$ represented as a combination of lava surface area and temperature.
Hashimoto and Imamura [2001] estimate a blurring of a point source full width at half maximum ( $\left.\mathrm{FWHM}=2 \sigma_{\mathrm{TOA}} \sqrt{2 \ln 2}\right)$ of $90 \mathrm{~km}$. The blurring represented by equation (1) means that the maximum radiance at the cloud level is much reduced compared to the radiance of a hot surface, small compared to $\sigma_{\mathrm{TOA}}$. The eruption anomaly is however observable over a much larger area than the flow and thus more reliably detected at a spatial resolution of tens of kilometers.

\subsection{Thermal Emission}

The surface thermal emission is, in absence of local heat sources, constrained by the atmospheric temperature [e.g., Lecacheux et al., 1993]. Modeling and descent probe data indicate that the atmospheric temperature $T_{\text {a }}$ closely follows the adiabatic gradient [Seiff et al., 1985] and therefore can be represented near the surface by

$$
T_{\mathrm{a}}(Z)=735 \mathrm{~K}-8.06 \mathrm{~K} / \mathrm{km} Z
$$

where $T_{\mathrm{a}}(Z)$ is the temperature at altitude $Z$ above mean planetary radius (MPR $=6052 \mathrm{~km}$ ) [Ford and Pettengill, 1992]. The small diurnal, latitudinal, and seasonal changes of atmospheric temperature [Stone, 1975] allow the assumption that the surface has the same temperature as the atmosphere of the same altitude [Lecacheux et al., 1993]. The thermal emission specific radiance of a surface is the product of emissivity $0<\varepsilon<1$ and the black body radiation $B$ given by Planck's law

$$
B(\lambda, T)=\frac{2 h c^{2}}{\lambda^{5}} \frac{1}{\exp \left(\frac{h c}{k_{b} \lambda T}-1\right)}
$$

where $h$ is the Planck constant $\left(6.6260755 \times 10^{-34} \mathrm{~J} \mathrm{~s}\right), c$ is the speed of light $(299792458 \mathrm{~m} / \mathrm{s}), k_{b}$ is the Boltzmann constant $\left(1.380658 \times 10^{-23} \mathrm{~J} / \mathrm{K}\right), \lambda$ is wavelength, and $T$ is the temperature of the emitting surface.

Since most lava flows are small compared to the blurring effect represented by $\sigma_{\text {TOA }}=38 \mathrm{~km}$, they cannot be resolved. Treating them as point sources can be accomplished by integrating thermal emission over the flow area minus thermal emission of the surface covered by the flow, thus the excess thermal emission $E$ is

$$
E=\int_{A} B(T(S))-B\left(T_{\mathrm{a}}(Z(S))\right) \mathrm{d} S
$$

The black body radiance of a surface at Venus temperature of $735 \mathrm{~K}$ and $1.02 \mu \mathrm{m}$ wavelength is $0.5 \mathrm{~W} \mu \mathrm{m}^{-1} \mathrm{sr}^{-1} \mathrm{~m}^{-2}$, which represents the background from which $E_{\mathrm{TOA}}$ must be distinguished to detect an eruption. Shalygin et al. [2015] interpret an observed 25\% radiance anomaly as active eruptions distributed over a distance of $100 \mathrm{~km}$. A $25 \%$ maximum increase in $E_{\mathrm{TOA}}$ can be expressed as an excess area integrated thermal emission $E=1 \mathrm{GW} \mu \mathrm{m}^{-1} \mathrm{sr}^{-1}$.

The area-integrated thermal emission can also be represented by the uniform temperature that a lava flow of a given area needs to have to introduce this excess emission [Hashimoto and Imamura, 2001, Figure 4]. Figure 1

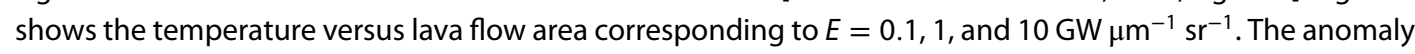
observed by VMC is thus consistent with a lava surface of $10 \mathrm{~km}^{2}$ at $1000 \mathrm{~K}$. This requires large and intense eruptions, because exposed lava surfaces cool below $1000 \mathrm{~K}$ within minutes [Head and Wilson, 1986; Griffiths and Fink, 1992; Bridges, 1997]. Most eruptions on Earth do not cover such large areas within minutes [e.g., Pieri and Baloga, 1986].

Hashimoto and Imamura [2001] hypothesize that it might be possible to detect such flows nevertheless, because the hottest parts of the flows, lava freshly exposed at the vent or fractures, contribute disproportionately to the area-integrated thermal emission; only $0.2 \mathrm{~km}^{2}$ at a typical basalt eruption temperature of $1400 \mathrm{~K}$ already corresponds to $E=1 \mathrm{GW} \mu \mathrm{m}^{-1} \mathrm{sr}^{-1}$. However, there are few remote sensing observations of eruptions that indicate that the $1 \mu \mathrm{m}$ thermal emission exceeds $E=1 \mathrm{GW} \mu \mathrm{m}^{-1} \mathrm{sr}^{-1}$. There may be long-lived eruptions 
on lo with approximately $0.1 \mathrm{GW} \mu \mathrm{m}^{-1} \mathrm{sr}^{-1}$ thermal emission at $1 \mu \mathrm{m}$ [Davies, 2003, Figures $1 \mathrm{e}$ and $1 \mathrm{~g}$ ] and

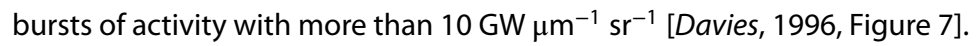

\section{VIRTIS Observations}

The infrared imaging channel of VIRTIS on Venus Express [Piccioni et al., 2007] is a line scanning spectrometer with an instantaneous field of view of $0.25 \times 64 \mathrm{mrad}$, corresponding to an apocenter nadir spatial resolution of $15 \mathrm{~km}$ on the cloud top level. This field of view is diffracted across an actively cooled detector with 256 spatial samples and 432 bands between $\sim 1$ and $5 \mu \mathrm{m}$. The set of data acquired instantaneously is called a frame, the subset of a frame at fixed wavelength, a line. A scanning mirror with 256 positions is used to acquire frames while scanning across the target, and the data are combined into a multispectral data cube, usually with 256 samples, 256 lines, and 432 bands. The number of lines can vary, and for some observations, on board binning of four samples times four lines is performed to reduce data volume.

For this study 1371 nightside images are selected based on criteria similar to those given in the work of Mueller et al. [2008]. Only surface areas that have been repeatedly observed by VIRTIS are included in the analysis, which excludes most of the northern hemisphere. The varying orbital distances and the spatial summing of pixels lead to a range of surface-sampling distances between 10 and $80 \mathrm{~km}$ within this data set. The actual spatial resolution of the surface imaging is however limited by the atmospheric blurring to $100 \mathrm{~km}$ [Hashimoto and Imamura, 2001].

Only two bands of each VIRTIS cube are used, located at the peaks of the spectral windows at $1.02 \mu \mathrm{m}$ and $1.31 \mu \mathrm{m}$. In the $1.02 \mu \mathrm{m}$ window gaseous absorption is small and radiation originating at the surface penetrates the atmosphere. Scattering in the clouds of varying opacity modulates the surface signal at $1.02 \mu \mathrm{m}$. Cloud opacity similarly affects the atmospheric emission at $1.31 \mu \mathrm{m}$ [Grinspoon et al., 1993; Meadows and Crisp, 1996]. At this wavelength the contribution from the surface is small and most of the radiation originates from the atmosphere in 20-30 km altitude, which shows little horizontal temperature variation [Seiff et al., 1985]. The $1.31 \mu \mathrm{m}$ emission can therefore be used to correct the $1.02 \mu \mathrm{m}$ emission for cloud opacity [Meadows and Crisp, 1996; Hashimoto and Sugita, 2003].

\section{Data Processing}

\subsection{Surface Thermal Emission}

The data processing is described in more detail in the work of Mueller et al. [2008]. The radiances observed at the top of the atmosphere with VIRTIS band $0(\approx 1.02 \mu \mathrm{m})$ and band $30(\approx 1.31 \mu \mathrm{m})$ are corrected for stray light and limb darkening. An example for the uncorrected band 0 image is shown in Figure $2 a$, Band 30 radiance $I_{30}$ originates in the atmosphere below the clouds and thus gives evidence of the local transmittance of clouds. The band 0 is then corrected for cloud contrast using the approach from Mueller et al. [2008] based on the analytical two stream approximation of Hashimoto and Sugita [2003]. The resulting image of surface thermal emission $I_{\text {surf }}$ as it would appear at the origin of the $1.31 \mu \mathrm{m}$ radiation is shown in Figure $2 \mathrm{~b}$. This image shows higher topography as dark spots due the lower surface temperature although the contrast is diminished by atmospheric extinction in the atmosphere near the surface. Additionally, the image contains a contribution of surface emissivity.

Disentangling these contributions is a difficult and not well-constrained problem [e.g., Kappel et al., 2015]; however, here we only need to look for transient variations. The median over time of VIRTIS measurements $\left\langle I_{\text {surf }}\right\rangle$ is an estimate of the local background. A map of this median of brightness temperature $B^{-1}\left(\left\langle I_{\text {surf }}\right\rangle\right)$ of a similar data set can be found in Figure 11 of Mueller et al. [2008]. To isolate the radiance variation on short timescales, the time average of thermal emission $\left\langle I_{\text {surf }}(x)\right\rangle$ interpolated to each imaged pixel center at place $x$ is subtracted from each image pixel. The resulting measured excess emission relative to the background $\left\langle I_{\text {surf }}(x)\right\rangle$ is

$$
E_{\mathrm{VIRTIS}}(x)=I_{\text {surf }}(x)-\left\langle I_{\text {surf }}(x)\right\rangle
$$

An example image of $E_{\mathrm{VIRTIS}}$ is shown in Figure 2c. This subtraction of the time average means that the search is not sensitive to eruptions lasting, with little change, longer than the time of observations of less than 800 days. 

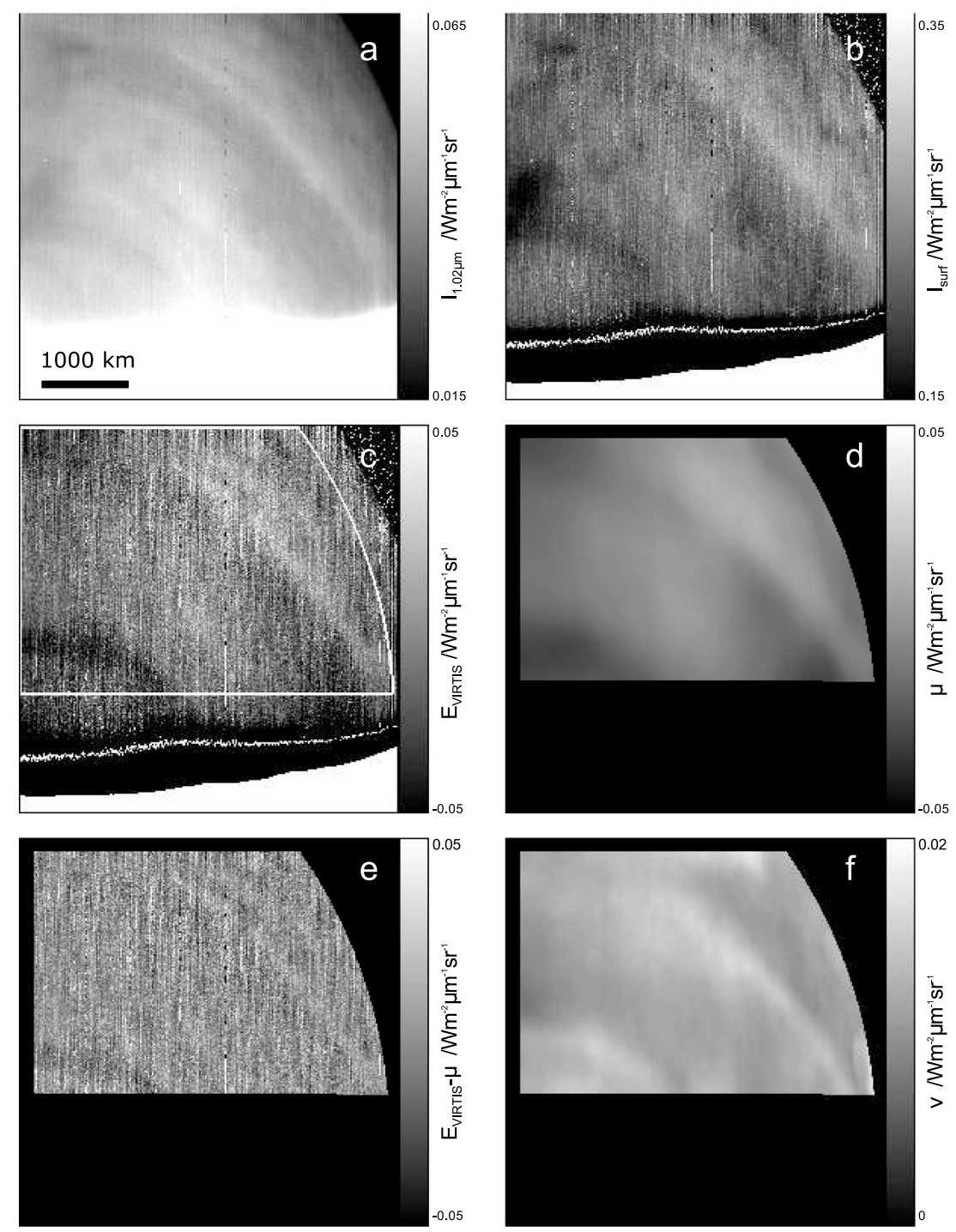

Figure 2. Illustration of data processing and filtering. (a) VIRTIS image VI0377_01 at $1.02 \mu \mathrm{m}$ centered at $59.09^{\circ} \mathrm{S} 48.42^{\circ} \mathrm{E}$. The lower right corner is at $-87.35^{\circ} \mathrm{S} 52.30^{\circ} \mathrm{E}$. The image shows the planets limb in the upper right corner and the terminator at the bottom. (b) Image corrected for stray light, limb darkening and clouds $\left(I_{\text {surf }}\right)$. Some coherent dark spots correspond to higher elevations, e.g., the $2800 \mathrm{~m}$ above MPR high volcano Erzulie Mons at $68^{\circ} \mathrm{S} 8^{\circ} \mathrm{E}$, center left side of the image. (c) Deviation of thermal emission from long-term average measured by VIRTIS ( $\left.E_{\mathrm{VIRTIS}}\right)$. Outlined is the area that contains data considered valid. (d) Moving average of a $700 \mathrm{~km}$ wide circle on the cloud surface $(\mu)$, calculated for distances greater than $150 \mathrm{~km}$ of invalid pixels. (e) High pass-filtered image: (d) subtracted from Figure 2c. Residual effect of clouds is reduced. (f) Noise estimated from the median absolute deviation within each search circle.

\subsection{Filtering and Noise Estimate}

Errors in $E_{\mathrm{VIRT}}$ that are systematically correlated over distances larger compared to $\sigma_{\mathrm{TOA}}$ do not necessarily interfere with the identification of anomalies in the shape of $E_{\mathrm{TOA}}$. There are several sources for such errors: shifts in the wavelength registration and bandwidth between images and steadily varying with pixel position on the detector [Bézard et al., 2009], insufficient stray light correction [cf. Mueller et al., 2008; Kappel et al., 2012], residual cloud error [Kappel et al., 2015], and incorrect flat field calibration [Kappel et al., 2012]. In addition to these systematic error sources, there is instrumental noise, which varies with internal temperature of the instrument, image exposure time, and radiation exposure. Instrumental noise is affected by the data processing, i.e., can be expected to increase according to the adjustments made for limb darkening and cloud opacity. 
We estimate representative errors from the deviations of $E_{\mathrm{VIRTIS}}(x)$ from zero. In order to estimate the local systematic error and noise, we employ a moving average with a diameter that is larger than the FWHM of eruption anomalies, but not yet large compared to the correlation length of cloud properties of $500 \mathrm{~km}$ [Kappel et al., 2012]. For each pixel (with footprint center location $x$ ) we define a neighborhood $o(x)$ based on the distances $I_{i}(x)$ to all pixels in the same image, where $i$ is an identifying integer $i=1,2,3 \ldots n$ and $n$ is the number of valid pixels in the image. The distances are calculated relative to the centers of the pixel footprints $x_{i}$ on the cloud reference level of $60 \mathrm{~km}$ above the mean planetary radius. The neighborhood $o(x)$ is defined as a set of all $i$ with the condition $l_{i}(x)<350 \mathrm{~km}$.

The median is a robust estimator for the expectation value of a distribution [Press et al., 1992], and we define the large-scale (compared to eruption anomalies) error component $\mu$ as

$$
\mu(x)=\overline{E_{\mathrm{VIRTIS}}\left(x_{i}\right)}, i \in o(x)
$$

where the horizontal line above an expression denotes the median. In order to avoid edge effects, we do not use pixels with footprints within $150 \mathrm{~km}$ distance to the edge or any invalid pixels. The white outline in Figure $2 \mathrm{c}$ shows the valid part of an example image, with the $\mu$ derived in this part shown in Figure $2 \mathrm{~d}$. Over all images, $\mu$ takes on values between $\pm 0.02 \mathrm{~W} \mathrm{~m}^{-2} \mu \mathrm{m}^{-1} \mathrm{sr}^{-1}$ in $95 \%$ of pixels. This corresponds to a residual atmospheric and large spatial scale instrumental noise of $2 \%$ relative to the average background $\left\langle I_{\text {surf }}\right\rangle$.

Subtracting $\mu(x)$ from $E_{\text {VIRTIS }}(x)$ is a moving average high-pass filter that leaves the anomalies of active eruptions and also pixel noise mostly intact. An example of the filtered image is shown in Figure 2e. For a detection of active volcanism the anomaly must be distinguishable from noise, which causes $E_{\mathrm{VIRTIS}}\left(x_{i}\right)$ to scatter around $\mu(x)$. The median absolute deviation is a robust estimator for the width of a distribution [Press et al., 1992], i.e., in this case the instrumental noise and small-scale error distributions, and we define the noise level $v$ as

$$
v(x)=\overline{\left|E_{\mathrm{VIRTIS}}\left(x_{i}\right)-\mu(x)\right|}, i \in o(x)
$$

Ninety-five percent VIRTIS data show values of $\nu<0.03 \mathrm{~W} \mathrm{~m}^{-2} \mu \mathrm{m}^{-1} \mathrm{sr}^{-1}$. The average of $I_{\text {surf }}$ is $0.24 \mathrm{~W} \mathrm{~m}^{-2}$ $\mu \mathrm{m}^{-1} \mathrm{sr}^{-1}$, thus, the signal-to-noise ratio (SNR) of the filtered data is 16 .

\subsection{Thermal Emission Scaling}

The derived thermal emission $I_{\text {surf }}$ includes the unknown factors of surface emissivity and lower atmosphere extinction, which need to be accounted for when comparing the local excess thermal emission $E$ derived from $I_{\text {surf }}$ to modeled black body radiation from lava flows. We estimate the corresponding scaling factor from the ratio of observed thermal emission to the black body radiance at surface temperature predicted from descent probe data $T_{a}(Z)$ and Magellan altimetry $Z$. We use the Magellan Global Topography Data Record [Ford and Pettengill, 1992] version 2.3 [Rappaport et al., 1999] and a Venus rotation period of 243.023 days which best aligns VIRTIS and Magellan altimetry data [Mueller et al., 2012].

Mueller et al. [2008] fit the observed brightness temperature equivalent to $I_{\text {surf }}$ as a polynomial of surface elevation $Z$ at $1.02 \mu \mathrm{m}$ wavelength:

$$
\begin{aligned}
T_{b}(Z)= & 707.218 \mathrm{~K}-4.731 \mathrm{~K} \mathrm{~km}^{-1} Z \\
& -0.484869815 \mathrm{~K} \mathrm{~km}^{-2} Z^{2}
\end{aligned}
$$

The scaling factor is thus

$$
T_{\mathrm{ra}}(Z)=\frac{B\left(T_{b}(Z)\right)}{B\left(T_{a}(Z)\right)}
$$

$T_{\text {ra }}$ varies from 0.38 at the lowest topographic range of $Z=-2 \mathrm{~km}$ to 0.53 at the highest elevations frequently observed by VIRTIS ( $Z=3 \mathrm{~km}$ ). If active lava flows have a higher emissivity than weathered background as proposed by Smrekar et al. [2010], this factor would slightly underestimate modeled thermal emission.

\subsection{Monitoring Parameterization}

Hashimoto and Imamura [2001] consider to use the measured maximum thermal emission anomaly in excess of the noise level as an active flow detection criterion, assuming a signal-to-noise ratio of 10. The VIRTIS data show variable noise and contain many outliers that would result in many false positives for such a criterion.

In case of an actual volcanic eruption, the half maximum of the anomaly (equation (1)) would stretch over at least three by three pixels of a high-resolution VIRTIS image with $20 \mathrm{~km}$ spatial resolution. A more 
Table 1. Number of Positives Returned by the Search Algorithm for Various Detection Criterion Parameters ${ }^{a}$

\begin{tabular}{lcccc} 
& $K=6$ & $K=7$ & $K=8$ & $K=9$ \\
\hline$L=2$ & $14,599 / 728$ & $3,037 / 449$ & $848 / 168$ & $224 / 56$ \\
$L=3$ & $1,814 / 150$ & $170 / 38$ & $60 / 16$ & $28 / 10$ \\
$L=4$ & $917 / 64$ & $37 / 8$ & $19 / 5$ & $7 / 3$ \\
$L=6$ & $404 / 29$ & $17 / 6$ & $8 / 3$ & $3 / 2$ \\
$L=10$ & $84 / 12$ & $1 / 1$ & $0 / 0$ & $0 / 0$ \\
\hline
\end{tabular}

${ }^{\mathrm{a}}$ The total number of pixels searched is $\simeq 2.5 \times 10^{7}$. Before the slash: number of positive pixels; after the slash: number of images containing positives. robust criterion than the single-pixel criterion of Hashimoto and Imamura [2001] is therefore that several neighboring pixels exceed the noise background level. Although we call $v$ instrumental noise, we cannot reliably calculate the probability that several neighboring values of $E_{\mathrm{VIRTIS}}\left(x_{i}\right)-\mu(x)$ exceed a value proportional to $v(x)$ by accident. This is because we do not know the local distribution of noise and more importantly because the noise is not completely random. Cosmic ray hits in the detector electronics can result in horizontal and vertical stripes (see Figure 2), the deviation from the true value of each pixel is in this case not independent from that of neighboring pixels.

We can, however, take the VIRTIS data as a large number of realizations of the nearly random process causing the noise. This characterizes the detection criterion in relation to the noise, provided that the number of data showing nonnoise signals is small compared to the number of data showing only noise. Thus, we assume that the number of eruptions occurring on Venus within the observation period is small compared to the number of spectra, which is $\simeq 2.5 \times 10^{7}$. This characterization allows us to assess the sensitivity of the criterion and to compare it to the capability of a visual inspection of images as in the work of Shalygin et al. [2012].

The detection criterion is incorporated in a search algorithm that investigates every VIRTIS pixel with eight valid neighbors and with a footprint center at least $150 \mathrm{~km}$ distant from any pixel on the image border, any pixel with an emission angle greater than $70^{\circ}$, or a pixel line with sunlight incidence angle greater than $96^{\circ}$. Around each of these pixels, a three by three pixel neighborhood is defined so that the locations of the footprint centers are $x_{i}$ where $i$ is an identifying integer $i=0,1,2, \ldots 8$. The $x_{0}=x$ corresponds to the central pixels and the other pixels footprint places are attributed with indexes increasing in order of their cloud top distances $I_{i}$ from the central pixel, i.e., $I_{0}=0 \mathrm{~km}<I_{1}<I_{2} \ldots<I_{8}$.

The algorithm counts a pixel as positive when $K$ pixels in this neighborhood exceed $L v\left(x_{0}\right)$. Table 1 presents the number of positive pixels and the number of images containing positive pixels for $K=6,7,8,9$ and $L=2,3,4,6,10$. Figure 3 shows an example of a positive at the detection criterion $K=7$ and $L=3$. At this detection criterion a positive is relatively rare, with 170 occurrences in 25 million searched pixels. These 170 positives are found in 38 of 1371 images and are typically clustered, e.g., when two or more of the short vertical stripes are adjacent. In image VI0377_01, only a single pixel qualifies. The upper white box in Figures 3a and $3 b$ is centered on the positive. Figure $3 c$ shows an enlarged version of the box. Figure $3 e$ shows the filtered radiance values in the vicinity of $x_{0}$ plotted against $l_{i}\left(x_{0}\right)$ with $1 v\left(x_{i}\right)$ error bars.

In order to evaluate our positives, we model an eruption signature for comparison. For an eruption at $x_{0}$, the expected value of excess radiance would decrease with distance similar to a Gaussian distribution with FWHM of $90 \mathrm{~km}$ [Hashimoto and Imamura, 2001]. The eruption anomaly $E(x)$ that raises the expected $E_{\mathrm{TOA}}$ value of the $K$ closest pixels above the detection threshold (solid line in Figure $3 e$ ) is determined by setting $E_{\mathrm{TOA}}\left(I_{(K-1)}\right)$ equal to $L v(x)$ in equation (1):

$$
E(x)=\frac{L v(x) 2 \pi \sigma_{\mathrm{TOA}}^{2}}{T_{\mathrm{ra}} \exp \left(-\frac{l_{(K-1)}^{2}}{2 \sigma_{\mathrm{TOA}}^{2}}\right)}
$$

The box in the center of the image in Figure $3 \mathrm{~b}$ shows where such an anomaly is added to the image in order to visualize the appearance of an active eruption matching the detection criterion. The comparison of the detected positive (Figure $3 \mathrm{c}$ ) with the simulated eruption image (Figure 3d) shows that this positive is very likely false, i.e., not an actual eruption. The same is obvious in Figure 3e, where at distances of 30-60 km from the positive the radiances do not scatter around the increased radiance expected from an eruption.

All other positives are also very likely false positives and more clearly identifiable as such. In most cases the positives are associated with one or more of the short vertical stripes of outlying data also visible in image VI0377_01 (Figures 2 and 3). In case of the more sensitive detection criterions, i.e., those with more positives, 

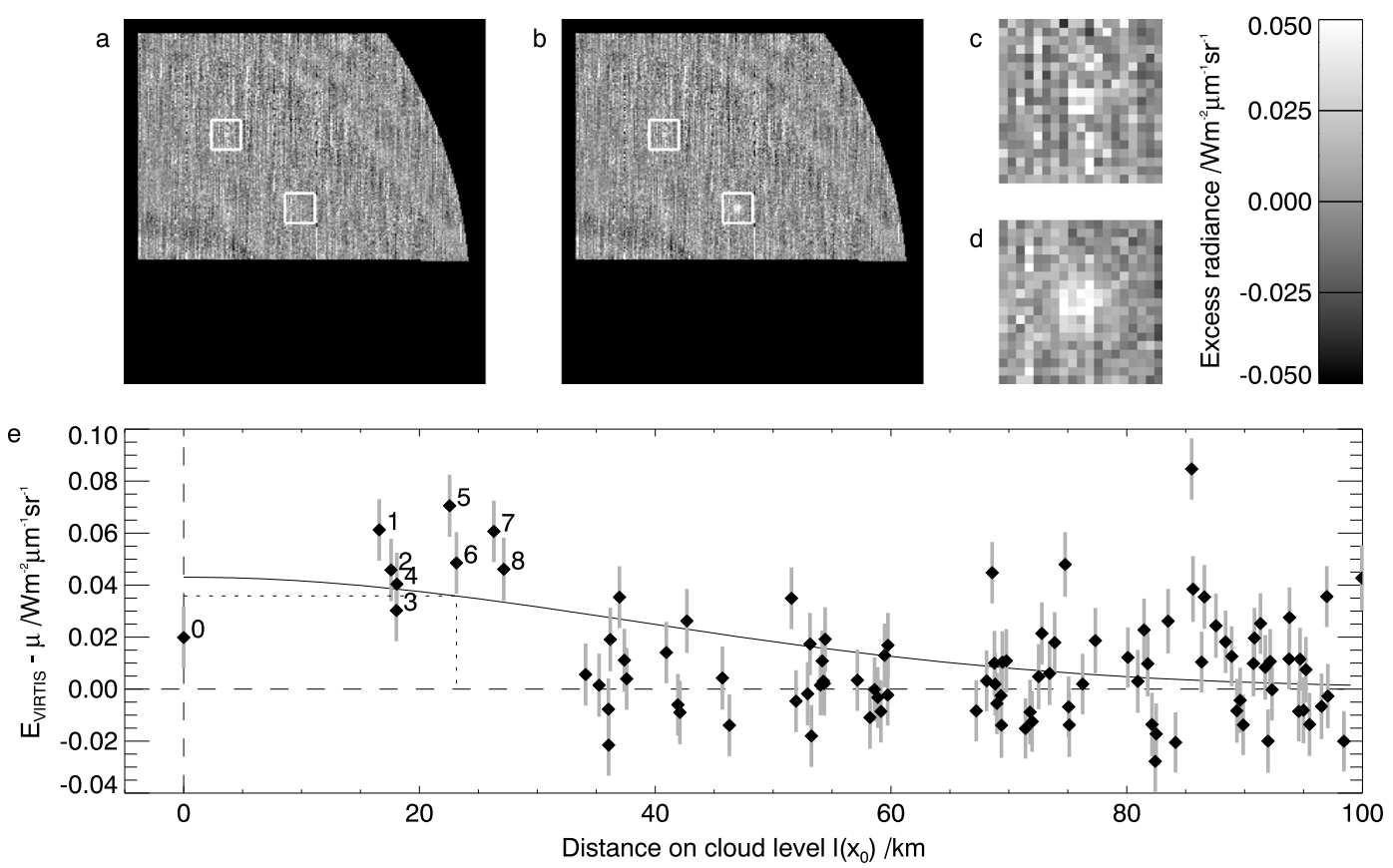

Figure 3. Illustration of the identification of a false positive and of a Gaussian anomaly matching the detection criterion. (a) Original high pass-filtered image (see Figure 2a) is centered on positive with respect to the search criterion, i.e., 7 pixels in a $3 \times 3$ neighborhood exceeding 3 times the noise level $v$, center box for reference with (b) original plus Gaussian anomaly matching the detection criterion. (c and d) Blowup of the two boxes in Figure $3 b$; (e) radiance values plotted against distance from the positive pixel, center of the upper left box in Figures $3 \mathrm{a}$ and $3 \mathrm{~b}$, labeled with $i$. The dashed lines indicate zero distance and excess radiance, the dotted lines indicate $I_{K-1}$ and $L v(x)$ for $K=7$ and $L=4$, which define a profile of detectable $E_{\mathrm{TOA}}$ by $E_{\mathrm{TOA}}\left(I_{(K-1)}\right)$ equal to $L v(x)$ (solid line).

we are unable to visually distinguish between false and true positives. Therefore, the detection criterion $K=7$ and $L=3$ approximately parameterizes the lower bound of our ability to visually identify eruptions.

An eruption with such an excess thermal emission $E$ would however not necessarily be detected. In a simple experiment we set up a program to add synthetic anomalies calculated with equations (10) and (1) in images and at locations chosen by a random number generator. One of the authors searched through all images for the hidden anomalies. For the criterion $K=7$ and $L=3,17$ out of 21 simulated eruptions were correctly identified, corresponding to a frequency of false negatives of $19 \%$.

The same experiment was conducted for the search algorithm, however, with a simulated eruption added to the neighborhood around every searched pixel. At the criterion $K=7$ and $L=3$ the probability of false negatives was $73 \%$. However, this calculation only applies to eruption anomalies that marginally match the detection criterion. For eruptions with $33 \%$ higher excess emission than matching the criterion, i.e., using $L=4$ instead of $L=3$ for the calculation of $E$ in equation (10), the probability of false negatives is already reduced to $22 \%$ and to less than $2 \%$ for $L=6$. Overall, the excess emission $E(x)$ (equation (10)) corresponding to $K=7$ and $L=4$ is a conservative criterion for a visible eruption. $L=3$ and $L=6$ bracket a confidence interval corresponding to the probability $<81 \%$ to detect an eruption with $L<3$ and the probability $<2 \%$ to miss an eruption with $L>6$.

\subsection{Constraint on the Frequency of Eruptions}

We have searched visually through all images of $I, I_{\text {surf }}$, and $E_{\text {VIRTIS }}$ for signatures of eruptions but did not detect any. Nevertheless, a portion of the surface of Venus has been monitored and $E$ (equation (10)) provides an estimate of the excess thermal emission that we would have detected, depending on noise and image resolution. This provides a constraint on the frequency of eruptions. However, we need to make an assumption about the duration for which the eruptions are typically detectable, because longer eruptions have a higher chance to coincide with the imaging. On the other side, there are often many VIRTIS images showing the same area on the same day. These do not each provide an independent constraint because all would observe the same eruption. 


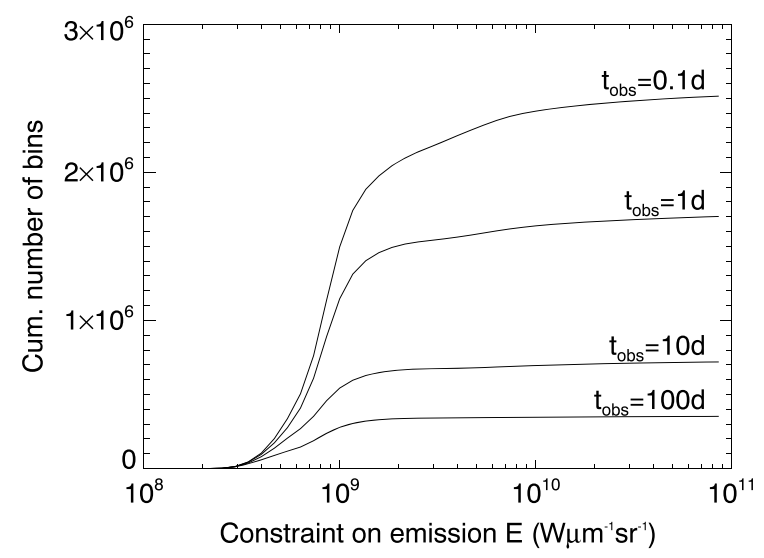

Figure 4. Representation of the constraint on volcanic activity by VIRTIS. Each bin corresponds to the monitoring of a surface tile of $50 \mathrm{~km} \times 50 \mathrm{~km}$ for a variable time $t_{\text {obs }}$. Shown is the cumulative number of bins that allow to reject the possibility of an eruption with thermal emission $\geq E$ occurring in that bin.
In order to find a simple estimate of the effect of eruption duration, we assume that the window for detecting an active eruption is $t_{\mathrm{obs}}=0.1$, 1, 10, or 100 days. Eruptions on Earth exhibit longer durations than these intervals but the eruption phases with high effusion rates and high thermal emission typically last hours to a few days [Wadge, 1981; Harris et al., 2000]. Eruptions that last much longer than 100 days may be difficult to distinguish from the background created by averaging thermal emission from a period of less than 800 days.

To calculate the total constraint on eruption frequency, the VIRTIS data set is separated into bins defined by surface area interval $d^{2}$ and time intervals $t_{\mathrm{obs}}$. The images containing $E$ are transformed to a sinusoidal, equal area map projection with a surface tile size of $d^{2}=50 \times 50 \mathrm{~km}^{2}$. If there are several images of the same tile within the same $t_{\text {obs }}$ interval, the tile is assigned the best constraint, i.e., the lowest $E$ value. The average of $E$ is variable mostly owing to the variable spatial resolution of the unprojected images. The coverage is tracked separately for arbitrary classes of $E$ with

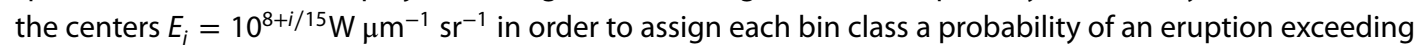
$E_{i}$ later. The number of bins for each $E_{i}$ is $M_{i}\left(t_{\text {obs }}\right)$. The cumulative number of bins which would detect signatures $>E_{j}$ is $\sum_{i=j}^{\infty} M_{i}$ and presented for different $t_{\mathrm{obs}}$ in Figure 4. The curves reach a value close to the maximum around $E_{15}=1 \mathrm{GW} \mu \mathrm{m}^{-1} \mathrm{sr}^{-1}$ thermal emission, which thus is the typical constraint that most of the VIRTIS images can impose.

Assuming that the probability that an eruption exceeds $E_{i}$ is $p_{i}$ and that the number of eruptions per unit surface area and unit time is $D$, the expected number of detected eruptions $N$ is

$$
N=\sum_{i=0}^{\infty} M_{i}\left(t_{\mathrm{obs}}\right) p_{i} D d^{2} t_{\mathrm{obs}}
$$

$M_{i}$ is small at $i>45$ and thus we evaluate the sum only up to $i=45$. Assuming that $t_{\mathrm{obs}}=1$ day, the cumulative VIRTIS monitoring with this or better capability corresponds to $\sum_{i=0}^{15} M_{i}=8.7 \times 10^{5}$ bins, each with a surface coverage of $d^{2}=50 \mathrm{~km} \times 50 \mathrm{~km}$. This therefore corresponds to monitoring of $2.2 \times 10^{9} \mathrm{~km}^{2}$ for 1 day, equivalent to the whole surface of the planet for 6.3 days. Assuming that eruptions are detectible $\left(p_{i}=1\right)$, the frequency of eruptions matching the observed number of eruptions $(N<1)$ is $D<0.5 \times 10^{-9} \mathrm{~km}^{-2} \mathrm{~d}^{-1}$. Obviously, eruptions are not necessarily detectible, and therefore, we need to model the thermal emission of eruptions in order to estimate $p_{i}$.

\section{Model of Eruption Thermal Emission}

We model active eruptions under Venus surface conditions to identify the eruption parameters that result in detectable total thermal emission in three successive steps. We calculate lava flow surface temperature $T_{0}$ as a function of time $T_{0}(t)$ following Bridges [1997] with some changes in parameters based on model of coupled radiative and convective heat loss in the infrared opaque atmosphere of Venus by Snyder [2002]. The model, the relevant parameters, and the results in comparison to field data from Earth is described in section 5.1. The resulting cooling curves are used as input for the model of flow surface temperature distribution in section 5.3. We assume that the flows on Venus have the same surface age distribution as lava flows on Earth of the same style. We derive the surface age distributions from temperature statistics of remote observations in the work of Wright et al. [2011]. The surface age distribution defines a weighted average $1.02 \mu \mathrm{m}$ brightness temperature for the flows. The radiating area of a flow is then assumed to be proportional to the effusion rate. 


\subsection{Lava Flow Surface Temperature}

We assume that eruptions on Venus have a basalt composition. This assumption is supported by the seven in situ measurements by the Soviet Venera landers, which gathered data consistent with mid-ocean ridge basalts in five sites and data consistent with more alkaline basalts in two sites [Surkov, 1983; Surkov and Barsukov, 1985; Surkov et al., 1986, 1987]. The assumption of basaltic composition is also supported by the morphology of the vast majority of volcanic features [e.g., Head et al., 1992a; Guest et al., 1992]. Basalt typically erupts close to its liquidus temperature and following Head and Wilson [1986] we assume a maximum eruption temperature $T_{s}$ of $1500 \mathrm{~K}$, and a minimum temperature of $1350 \mathrm{~K}$ consistent with the range of eruption temperatures used by Harris et al. [1997, 1998, 2000].

The cooling depends on the environmental temperature. The surface of Venus observed by VIRTIS has elevations between -2 and $4 \mathrm{~km}$. The atmospheric temperature $T_{a}$ is a function of altitude only and varies for this range between approximately 700 and $750 \mathrm{~K}$ [Seiff et al., 1985]. We found that variation of environmental temperature within this range does not result in significant changes in thermal emission and therefore set the temperature to that if the mean planetary radius: $T_{a}=735 \mathrm{~K}$. The surface of lava flows in an atmosphere cools by thermal emission and advection [e.g., Head and Wilson, 1986; Griffiths and Fink, 1992]. The heat flux density by thermal emission from a plane surface of temperature $T_{0}$ is

$$
q_{\mathrm{rad}}=\varepsilon_{\mathrm{eff}} \sigma_{B}\left(T_{0}^{4}-T_{a}^{4}\right)
$$

where $\sigma_{B}$ is the Stefan-Boltzmann constant, $\varepsilon_{\text {eff }}$ is the effective emissivity equivalent to the ratio of thermal emission integrated over the whole spectrum to the total black body radiation of temperature $T_{0}$, and $T_{\mathrm{a}}$ is the effective temperature of the environment of the lava flow, e.g., $\approx 303 \mathrm{~K}$ at the Hawaiian lava flows [Keszthelyi and Denlinger, 1996] and $735 \mathrm{~K}$ at the mean planetary radius of Venus [Seiff et al., 1985]. The $\varepsilon_{\text {eff }}$ is not well known as there are few laboratory measurements of emissivity over the range of lava flow temperatures and temperature has a significant influence on emissivity even at Venus ambient temperatures [e.g., Pieters et al., 1986; Helbert and Maturilli, 2009]. Keszthelyi and Denlinger [1996] use a value of 0.95 and Harris et al. [2000] a value of 0.99 , and Head and Wilson [1986] a value of 0.75 . We adopt $\varepsilon_{\text {eff }}=0.95$ consistent with laboratory measurements at Venus ambient temperatures [Helbert et al., 2017]. The effect of emissivity over the discussed range is on the order of $20 \%$, small compared to other factors.

Advection of heat occurs either by forced convection from wind moving over the flow or by free convection driven by the temperature contrast between flow temperature $T_{0}$ and atmosphere temperature $T_{\mathrm{a}}$. We use a convection heat flux coefficient $h_{\text {conv }}$ so that the cooling heat flux density is

$$
q_{\mathrm{conv}}=h_{\mathrm{conv}}\left(T_{0}-T_{\mathrm{a}}\right)
$$

Snyder [2002] points out that the infrared opaque $\mathrm{CO}_{2}$ atmosphere of Venus results in a coupling of radiative and convective heat flux. The thermal radiation is mostly absorbed in the lowest $10 \mathrm{~m}$ of the atmosphere and thereby reduces the atmosphere boundary layer gradient and thus free convection. The radiative heating of the atmosphere and reduced convective heat transport also affect $T_{a}$ and result in a lower radiative heat flux. The coupled radiative and convective heat flux found by Snyder [2002] is actually less than pure radiative heat flux into a constant Venus environment at lava temperatures above $1000 \mathrm{~K}$. In this case $h_{\text {conv }}=0 \mathrm{~W} /\left(\mathrm{m}^{2} \mathrm{~K}\right)$ is an approximation that overestimates heat flux density. Snyder [2002] states that the presence of wind complicates the situation although the radiative heating of the lowest atmosphere also reduces the efficiency of forced convection.

For an upper bound on the heat flux density by wind, we adjust the value of $h_{\text {conv }}=50 \mathrm{~W} /\left(\mathrm{m}^{2} \mathrm{~K}\right)[$ Keszthelyi et al., 2003] derived from temperature variations of Hawaiian pahoehoe lobes exposed to a $10 \mathrm{~m} / \mathrm{s}$ wind to Venus conditions. We assume that the coefficient is proportional to atmospheric density, specific heat capacity at constant pressure, and wind speed (compare equations (6)-(8) in the work of Keszthelyi and Denlinger [1996]). Griffiths and Fink [1992] provide density and heat capacity for the atmospheres of both Earth and Venus and winds speeds measured at the surface of Venus on the order of $1 \mathrm{~m} / \mathrm{s}$ [Avduevskijet al., 1971; Marov et al., 1973], and likely not larger than $2 \mathrm{~m} / \mathrm{s}$ [Lorenz, 2016]. This results in a forced convection coefficient $h_{\text {conv }}=208 \mathrm{~W} /\left(\mathrm{m}^{2} \mathrm{~K}\right)$.

This value is higher than the value of $59 \mathrm{~W} /\left(\mathrm{m}^{2} \mathrm{~K}\right)$ resulting from the theoretical calculations of forced convection by Head and Wilson [1986] and is of the same order of magnitude as the free convection coefficients 


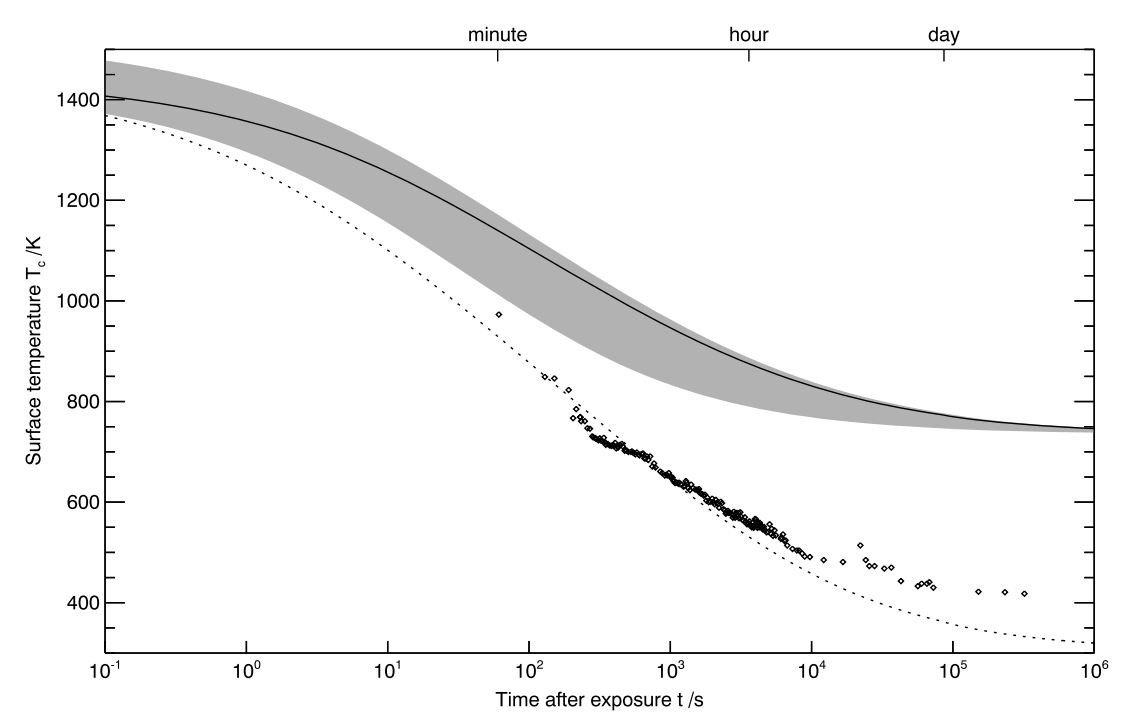

Figure 5. Cooling of lava surfaces under Earth and Venus conditions. Diamonds are the radiometer measurements at a cooling pahoehoe sheet flow of Kilauea (Hawaii, Earth) acquired on 17 April 1990 by Hon et al. [1994a, 1994b]. The dotted curve corresponds to $\phi=0.5$ and a constant convection coefficient of $h_{\text {conv }}=50 \mathrm{~W} \mathrm{~m}^{-2} \mathrm{~K}^{-1}$ [Keszthelyi and Denlinger, 1996]. Light grey area represents the lava surface temperatures at Venus with varying eruption temperature and convective heat flux coefficient as described in the text. The solid curve results from an eruption temperature of $1408 \mathrm{~K}$ and no convective heat flux.

of $162 \mathrm{~W} /\left(\mathrm{m}^{2} \mathrm{~K}\right)$ and $263 \mathrm{~W} /\left(\mathrm{m}^{2} \mathrm{~K}\right)$ calculated for a lava surface temperature of $1500 \mathrm{~K}$ by Head and Wilson [1986] and Griffiths and Fink [1992], respectively. The coefficients for free convection used by Head and Wilson [1986] and Griffiths and Fink [1992] are proportional to $\left(T_{0}-T_{\mathrm{a}}\right)^{1 / 3}$, thus a constant value at the upper bound on $h_{\text {conv }}$ results in higher heat fluxes for $T_{0}<1100 \mathrm{~K}$ than assumed in these studies. We assume a range of $h_{\text {conv }}=0-208 \mathrm{~W} /\left(\mathrm{m}^{2} \mathrm{~K}\right)$, encompassing all previous assumptions.

With the above values for initial lava temperature $T_{s}$ and heat flux density $q=q_{\text {rad }}+q_{\text {conv }}$ as function of lava surface temperature $T_{0}$ and environmental temperature $T_{a}$ we calculate the surface cooling curves following Bridges [1997] by numerically integrating

$$
T(t)=T_{s}-\int_{0}^{t} \frac{q\left(\lambda_{t}\right)}{\rho c_{p} \sqrt{\kappa \pi\left(t-\lambda_{t}\right)}} \mathrm{d} \lambda_{t}
$$

where $\rho$ is lava density, $c_{p}$ is lava specific heat capacity, and $\kappa$ is thermal diffusivity. Our numerical integration scheme was validated by comparison with the graphically presented cooling curves for mixed radiative and convective cooling of Bridges [1997].

The lava vesicularity $\phi$, i.e., the volume fraction of gas bubbles in the lava, affects the cooling curves [Keszthelyi and Denlinger, 1996]. Bridges [1997] evaluated the effect of increased atmospheric pressure on the properties of lava. By comparison with samples of submarine Hawaiian basalt from $900 \mathrm{~m}$ depth, Bridges [1997] inferred that the vesicularity of similar lava on the surface of Venus should be 0.1 or less. Following Bridges [1997], we assume that heat capacity $c_{p}=1200 \mathrm{~J} \mathrm{~kg}^{-1} \mathrm{~K}^{-1}$ and thermal diffusivity $\kappa=6 \times 10^{-7} \mathrm{~m}^{2} / \mathrm{s}$ are independent of vesicularity and that the density is

$$
\rho=(1-\phi) 3000 \mathrm{~kg} / \mathrm{m}^{3}
$$

Using this vesicularity and varying eruption temperature $T_{\mathrm{s}}$, environmental temperature $T_{\mathrm{a}}$, and convection heat flux coefficient $h_{\text {conv }}$, the lava flow surface temperatures fall within the light grey area in Figure 5.

\subsection{Temperature Model Verification}

This approach of Griffiths and Fink [1992] and Bridges [1997] for the calculation of cooling curves neglects the release of latent heat during the crystallization of lava. This is appropriate for the initial rapid cooling of the lava surface, because the upper few millimeters to centimeters are quenched to amorphous glass [e.g., Hon et al., 1994a]. Keszthelyi and Denlinger [1996] also model the temperature measurements by Hon et al. [1994a] 


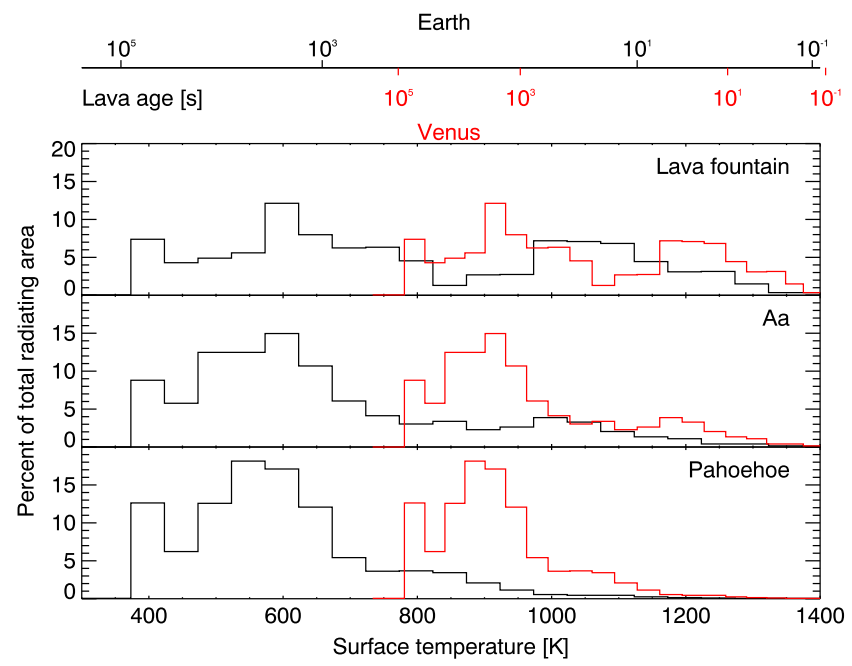

Figure 6. Black: Lava flow surface temperature distributions derived from Hyperion data [Wright et al., 2011] converted to Venus conditions assuming the temperature to age relations shown at the top, corresponding to the dotted and the solid line in Figure 5. and give the parameters $\phi=0.5$, $T_{\mathrm{s}}=1408 \mathrm{~K}$ and $T_{\mathrm{a}}=303 \mathrm{~K}$. With these parameters and a constant convection coefficient of $h_{\text {conv }}=50 \mathrm{~W} /\left(\mathrm{m}^{2} \mathrm{~K}\right)$, our models result in slightly too low temperatures (dotted curve in Figure 5). In effect, this will slightly underestimate the thermal emission of lava flows.

\subsection{Lava Flow Thermal Emission Model}

It is necessary to assume an age distribution for the modeled lava flows, in order to convert the cooling curves to surface temperature areal distribution. Wright et al. [2011] study hyperspectral imaging observations from the Hyperion sensor of the Earth Observing 1 spacecraft showing 61 lava flows of various types. They derive surface temperature distribution of the detectably emitting areas of the lava flow, limited by the sensor and background emission to temperatures $\gtrsim 400 \mathrm{~K}$. Lava flow styles relevant for Venus resurfacing are pahoehoe flows [Garvin et al., 1984], forming a relatively stable crust, channel fed aa flows [Bruno et al., 1992] with continually fractured and overturned crust, and lava fountains [Head and Wilson, 1986]. Wright et al. [2011] find that aa and fountains have a bimodal temperature distribution, as opposed to the unimodal distribution of pahoehoe flows. Wright et al. [2011] interpret this as a result of thermal renewal of the lava surface that is continuously exposing fresh lava in some areas of the flows.

We assume that the surface age distributions of Venusian flows are the same as on Earth, depending on flow type. The relation of temperature versus time shown in Figure 5 allows us to derive this age distribution from the Earth lava flow data of Wright et al. [2011] and then to calculate the temperature distributions of the Venus equivalents, shown in Figure 6

Our flow detection criterion is expressed in terms of thermal emission integrated over the area of the flow $E$. The derived Venus lava flow surface temperature distributions in Figure 6, i.e., area fractions $f_{i}$ at temperature $T_{i}$, can be expressed as average specific radiance at $1.02 \mu \mathrm{m}$ wavelength:

$$
I_{\text {eff }}=\sum_{i} f_{i} B\left(T_{i}\right)
$$

This average radiance $I_{\text {eff }}$ can be more intuitively expressed as brightness temperature $T_{b}=B^{-1}\left(I_{\text {eff }}\right)$. The effect of flow type, varying eruption temperature, and convective heat loss coefficient on average brightness temperature is shown in Figure 7.

In order to calculate the total thermal emission of the lava flow, we need an estimate of the emitting area. We assume that the emitting area is equivalent to the flow area emplaced within the time of the oldest age of the surface age distribution: $t_{\text {rad }}=33151 \mathrm{~s}$, approximately $9 \mathrm{~h}$. This neglects the contribution of older and cooler parts of the flow, which are however close to the background emission and do not contribute very much to the detectable signal. For eruptions lasting less than this time, we set $t_{\text {rad }}$ to the eruption duration. We assume a constant flow thickness $d_{c}$, and the emitting area is therefore determined by the effusion rate $F$ :

$$
A_{\mathrm{rad}}=F \frac{t_{\mathrm{rad}}}{d_{c}}
$$

Under these assumptions, total thermal emission is for a given effusion rate inversely proportional to flow thickness. We vary this parameters between $d_{c}=1 \mathrm{~m}$ and $d_{c}=20 \mathrm{~m}$, consistent with the modeling of flow geometry based on a Bingham rheology by Head and Wilson [1986].

The effusion rate of eruptions is proportional to thermal emission in this model and is the least bounded parameter. Eruptions on Earth typically have an eruption rate of a few cubic meters per second, but effusive 

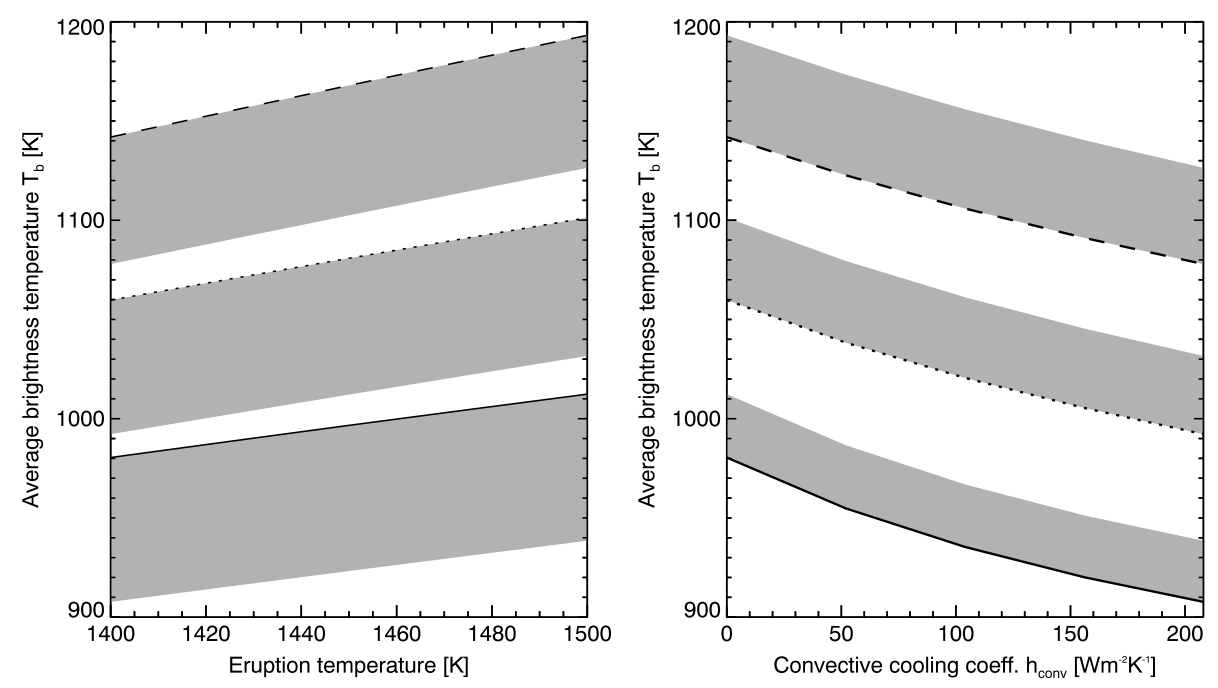

Figure 7. Modeled average brightness temperatures for pahoehoe flows (solid), aa flows (dotted), and lava fountains (dashed). The grey area shows the effect of the variation of convection coefficient on the left plot and eruption temperature on the right plot.

eruptions on the order of $10^{3} \mathrm{~m}^{3} / \mathrm{s}$ have occurred in historical time [e.g., Wadge, 1981; Thordarson and Larsen, 2007]. Venus features extremely large lava flow fields that were interpreted to be emplaced with eruption rates as high as $10^{7} \mathrm{~m}^{3} / \mathrm{s}$ [Roberts et al., 1992].

It is useful to express the proportionality of specific total excess thermal emission $E$ to effusion rate $F$ with a single visibility factor $\beta$ :

$$
E=\beta F=\frac{t_{\mathrm{rad}}}{d_{c}}\left[I_{\text {eff }}-B\left(T_{a}\right)\right] F
$$

We use units of $J \mu \mathrm{m}^{-1} \mathrm{sr}^{-1} \mathrm{~m}^{-3}$ for $\beta$ to emphasize that this is used to derive a specific radiance at $1.02 \mu \mathrm{m}$ wavelength.

To simplify further analysis, we limit the calculations to three sets of parameters that give the best guess and bounds of the problem. This set of parameters is eruption temperature typical for Hawaii $T_{s}=1425 \mathrm{~K}$ [Crisp and Baloga, 1990a], which is an underestimate for magma of the same composition on Venus [Head and Wilson, 1986], only radiative heat loss $h_{\text {conv }}=0 \mathrm{~W} \mathrm{~m}^{-2} \mathrm{~K}^{-1}$ at constant environmental temperature which is likely already an overestimate [Snyder, 2002], and a flow thickness of $5 \mathrm{~m}$. In comparison to the detection threshold

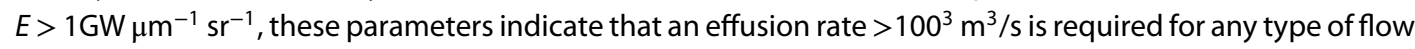
surface. Eruptions with such high effusion rates on Earth typically form aa flows [Rowland and Walker, 1990], possibly in addition to a lava fountain. We choose the aa-like surface age distribution as template for the best guess.

The three sets of parameter and corresponding visibility factors are given in Table 2. The typical detection threshold of $1 \mathrm{GW} \mu \mathrm{m}^{-1} \mathrm{sr}^{-1}$ means effusion rates of $37 \mathrm{~m}^{3} / \mathrm{s}, 833 \mathrm{~m}^{3} / \mathrm{s}$, and $31,250 \mathrm{~m}^{3} / \mathrm{s}$ are required for the optimistic, conservative, and pessimistic scenarios, respectively.

Table 2. Visibility Factors for Different Eruption Durations for the Pessimistic, Conservative, and Optimistic Sets of Assumptions ${ }^{a}$

\begin{tabular}{lccccc} 
Scenario & Flow Type & $h_{\text {conv }}$ & $l_{\text {eff }}$ & $d_{c}$ & $\beta$ \\
\hline Pessimistic & pahoehoe & 208 & 19 & 20 & $3.2 \times 10^{4}$ \\
Conservative & aa & 0 & 295 & 5 & $1.2 \times 10^{6}$ \\
Optimistic & lava fountain & 0 & 790 & 1 & $2.6 \times 10^{7}$ \\
\hline
\end{tabular}

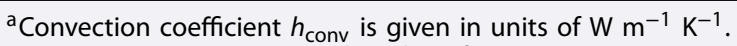
$l_{\text {eff }}$ is given in units of $W \mu \mathrm{m}^{-1} \mathrm{sr}^{-1} \mathrm{~m}^{-2}$. Flow thickness $d_{c}$ is given in meters. Visibility coefficient $\beta$ values given in units of $\mathrm{J} \mu \mathrm{m}^{-1} \mathrm{sr}^{-1} \mathrm{~m}^{-3}$. 


\subsection{Thermal Emission Model verification}

To test the model of flow growth, we compare it to the field and remote observations of the 1991 - 1993 Etna eruption studied by Harris et al. [1997] and Wooster et al. [1997]. The eruption began on 14 December 1991 and built a $5.5 \mathrm{~km}^{2}$ flow by 2 January 1992 at effusion rates of $15-18 \mathrm{~m}^{3} / \mathrm{s}$ [Global Volcanism Network, 1991]. The growth of the flow field over this period of 19 days indicates an areal coverage rate of $\approx 3.4 \mathrm{~m}^{2} / \mathrm{s}$, which means an average thickness of $\approx 5 \mathrm{~m}$. The effusion rate peaked in the first days of January at effusion rates $<25 \mathrm{~m}^{3} / \mathrm{s}$ and on 9 January the flow field reached an area of $6 \mathrm{~km}^{2}$ [GVN, 1992]. After 9 January, the eruption continued for more than a year at eruption rates of $6-8 \mathrm{~m}^{3} / \mathrm{s}$, with a mean rate of $6 \mathrm{~m}^{3} / \mathrm{s}$ derived from Global Positioning System measurements of the flow field [GVN, 1993]. The total flow field area at the end of the 473 day eruption was $7 \mathrm{~km}^{2}[G V N$, 1993].

Radiant heat flux-i.e., the thermal emission integrated over surface area, solid angle, and all wavelengths - is derived from the data from the Advanced Very High Resolution Radiometer (AVHRR) at 3.7, 11, and $12 \mu \mathrm{m}$ wavelengths [Harris et al., 1997] and from the Along Track Scanning Radiometer (ATSR) at 1.6 and $11 \mu \mathrm{m}$ wavelength [Wooster et al., 1997]. During the most intense phase in early January 1991, the peak radiant flux derived from AVHRR is 9-15.5 GW over an active area in the range of $1-6 \mathrm{~km}^{2}$ [Harris et al., 1997]. The peak radiant heat flux derived from ATSR data is between 4 and 7 GW [Wooster et al., 1997]. Our assumptions predict a radiating area of $0.2 \mathrm{~km}^{2}$ and a radiative heat loss of $4 \mathrm{GW}$ for the aa flow surface age distribution at $25 \mathrm{~m}^{3} / \mathrm{s}$. In the later phase from April 1992 to January 1993 the AVHRR-derived radiant flux remains approximately in the range $2.5-6 \mathrm{GW}$ with relatively little variation and an active area range of $0.5-3.5 \mathrm{~km}^{2}$. The radiant flux derived from ATSR data in this phase is between 1 and $3 \mathrm{GW}$ [Wooster et al., 1997]. Our approach predicts, for this phase with the above assumptions and an effusion rate of $6 \mathrm{~m}^{3} / \mathrm{s}$, a radiant flux of $0.9 \mathrm{GW}$ over a radiating area of $0.04 \mathrm{~km}^{2}$.

The difference between the radiant flux observed by AVHRR and our predicted values of radiant flux can at least partly be attributed to the surface temperature distribution from Hyperion data, which is not sensitive to temperatures $\lesssim 400 \mathrm{~K}$ [Wright et al., 2011]. We are however only interested in the $1.02 \mu \mathrm{m}$ thermal emission, which is less sensitive to these low temperatures than the radiant flux. Neglecting the low temperature areas therefore results in an underestimate of area integrated specific radiance $E$ by a factor of no greater than 3 . In light of the uncertainty from the other parameters, we consider this reasonable and all our estimates to be conservative.

\section{Constraint on the Rate of Volcanism}

\subsection{Expectation Values for the Number of Detected Eruptions}

In order to constrain the rate of volcanism $F_{\text {global, }}$ we need to compare the expected number of detected eruptions $N$ (equation (11)) with the number of eruptions actually detected. The number of eruptions unambiguously detected by VIRTIS is zero, and therefore, any rate and style of volcanism that would result in a large expectation value for the number of detected eruptions is improbable. In order to estimate this number $N$, we need an estimate of the probability $p$ so that an eruption is detectable, and an estimate of the frequency of all eruptions $D$.

The average volume of eruptions $\bar{V}$ relates the rate of volcanism $F_{\text {global }}$ to the average frequency of eruptions per unit area and unit time

$$
D=F_{\text {global }} \bar{V}^{-1} A_{\text {global }}^{-1}
$$

where $A_{\text {global }}=4.6 \times 10^{8} \mathrm{~km}^{2}$ is the surface area of Venus.

We can make an estimate of the highest possible expectation value for the number of detections (equation (11)) by assuming that all eruptions are exactly meeting the detection criterion $(F=$ $\left.1 \mathrm{GW} \mu \mathrm{m}^{-1} \mathrm{sr}^{-1} / \beta\right)$ and last exactly 1 day, giving the data from each Venus Express orbit an independent chance to detect an eruption. In the conservative case this theoretical eruption volume would be $F \times 1 \mathrm{~d}=0.072 \mathrm{~km}^{3}$, and a global rate of volcanism of $1 \mathrm{~km}^{3} / \mathrm{yr}$ would be equivalent to an eruption frequency $D=8.2 \times 10^{-11} \mathrm{~km}^{-2} \mathrm{~d}^{-1}$. Equation (11) gives then an expectation value of detections of $N=0.35$. Clearly, the VIRTIS data set is not sufficient to place a constraint on the rate of volcanism on the order of $1 \mathrm{~km}^{3} / \mathrm{yr}$, as any realistic assumption on the probability that an eruption is detectable will only lead to lower values of $N$.

There are some indications that Venus has Hawaii-like volcanism and that this type of eruption is the most frequent recently. So far, 10 topographic rises of Venus are proposed to be hot spots caused by deep mantle 


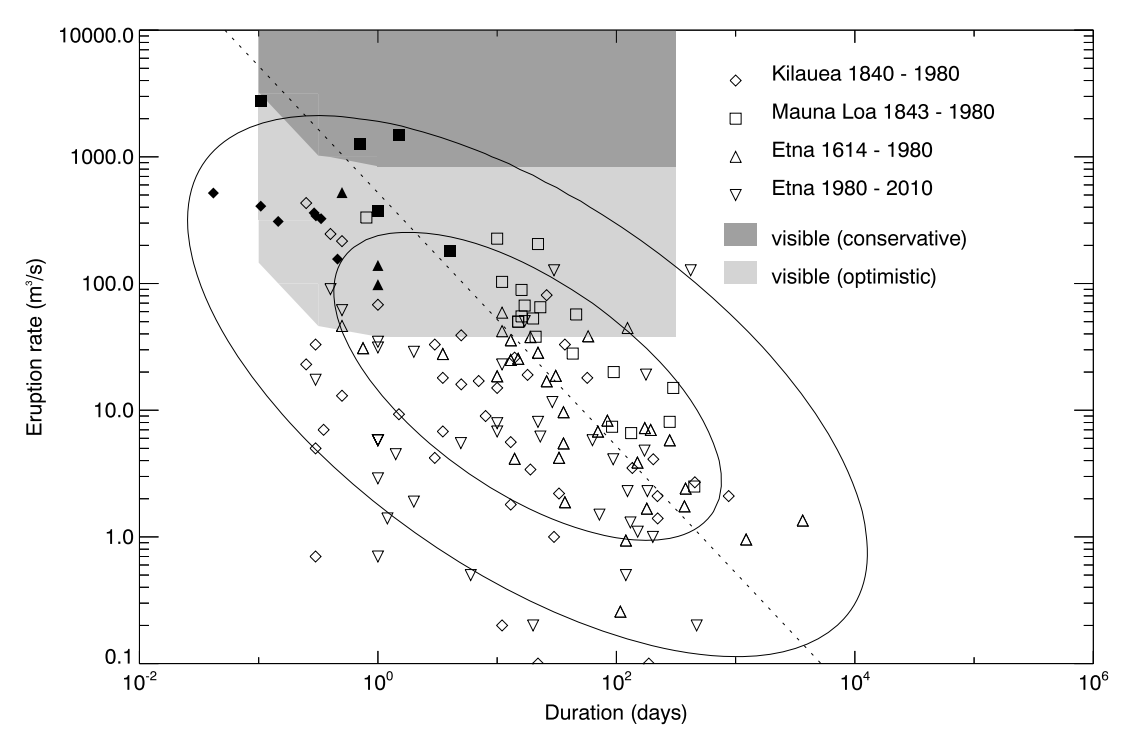

Figure 8. Historical eruptions of three terrestrial volcanos from the data collated by Wadge [1981] and after 1980 by Harris et al. [2011]. Filled symbols represent only the initial phase of a few of the most intense eruptions. Grey areas indicate combinations of effusion rate and eruption duration that would be detectable by VIRTIS under the optimistic and conservative sets of assumptions. The solid lines correspond to isolines of a fitted probability density function that encompass $95 \%$ and $68 \%$ of eruptions. The dotted line corresponds to a volume of $0.045 \mathrm{~km}^{3}$.

plumes analogous to the setting of Hawaii [e.g., Smrekar, 1994; Stofan et al., 1995; Ivanov and Head, 2010; Smrekar and Davaille, 2015]. The unusually high infrared emissivity at some of the volcanos associated with these hot spots has been interpreted as less weathered and thus recently emplaced flows [Smrekar et al., 2010]. The setting of the Hawaiian volcanos is similar to the conditions on Venus, in that they are situated in basaltic crust and far removed from plate boundaries. Stofan et al. [2001] studied three large volcanos on Venus and concluded that the overall history and style of volcanism is not fundamentally different from large terrestrial volcanos. That is characterized by variable rate of magma supply to a shallow, evolving storage system, from which, depending on local and regional stress fields, intrusive and extrusive volcanism of varying style emanates. Stofan et al. [2001] propose Mount Etna and Galapagos as terrestrial analogues for the three volcanos. However, based on the larger average diameter of calderas [Head et al., 1992b] and greater lengths reached by flows, Stofan et al. [2001] speculate that eruptions on Venus typically have larger volumes than on Earth, with likely both longer durations and higher effusion rates. Assuming Earth hot spot style effusive volcanism is thus a conservative estimate.

Wadge [1981] studies the style of volcanism using historical data from the two active Hawaiian volcanos and Mount Etna. The data on average effusion rate and eruption duration collated by Wadge [1981] is presented in Figure 8 together with the optimistic and conservative estimates on the visibility of eruptions, i.e., the erup-

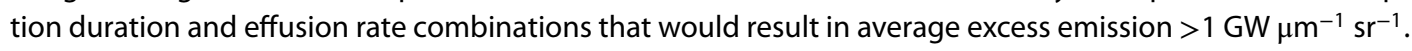
Under the conservative assumptions, some of the maximum effusion rates in the initial phases exceed the $800 \mathrm{~m}^{3} / \mathrm{s}$ required for detectability $\left(\beta_{\text {cons }}=1.2 \mathrm{~J} \mathrm{\mu m}^{-1} \mathrm{sr}^{-1} \mathrm{~m}^{-3}\right.$ ). Figure 8 also shows that $75 \%$ of these historical eruptions fall within the assumed eruption visibility duration range $t_{\mathrm{obs}}=0.1-100$ days. Furthermore, nearly all eruptions with potentially sufficient average effusion rates $\left(40 \mathrm{~m}^{3} / \mathrm{s}\right)$ are in this range, and there is a clear trend that longer eruptions have lower average effusion rates [Wadge, 1981].

To roughly estimate which fraction of eruptions occurring on Venus are detectable, we use the data of Wadge [1981] as an example of realistic statistics. The data cannot be seen as representative of Earth, sampling only three volcanoes, and because it is historical data gathered over 140 years and collected to study the mechanism of high effusion rates, might be biased toward more remarkable eruptions. The data of Mount Etna eruption from 1980 to 2010 gathered by remote sensing and reported by Harris et al. [2011] indeed show on average lower effusion rates; however, this could also be due to a change in the behavior of the volcano. Mauna Loa and Kilauea only had one eruption each in this period, with the latter being continuously active since 1983. Iceland historical and remotely observed eruptions tend toward higher effusion rates [Harris et al., 2000; Thordarson and Larsen, 2007]. Since Venus does not have anything resembling the location of Iceland at 
a divergent plate boundary, we use only the data from Mount Etna, Mauna Loa, and Kilauea. We fit the data of Harris et al. [2011] and Wadge [1981], including the data on peak effusion phases, with a two-dimensional lognormal probability density function pdf of eruption duration $t_{\text {erupt }}$ and average effusion rate $F$.

$$
\begin{gathered}
\text { pdf }=C_{0} \exp \left[-\frac{\left(x^{\prime} / C_{1}\right)^{2}+\left(y^{\prime} / C_{2}\right)^{2}}{2}\right] \\
x^{\prime}=\left(\log _{10} t_{\text {erupt }}-C_{3}\right) \cos C_{5}-\left(\log _{10} F-C_{4}\right) \sin C_{5} \\
y^{\prime}=\left(\log _{10} t_{\text {erupt }}-C_{3}\right) \sin C_{5}+\left(\log _{10} F-C_{4}\right) \cos C_{5}
\end{gathered}
$$

The fitted coefficients are $C_{0}=0.0022, C_{1}=5.88, C_{2}=1.36, C_{3}=0.52, C_{4}=1.26$, and $C_{5}=0.57$. The correlation between effusion rate and duration is such that high effusion rate eruptions on average have a lower volume [Wadge, 1981]. We calculate the probability that an eruption is detectable $p_{i}$ by numerical integration of pdf over the region where area integrated emission exceeds the detection threshold $E_{i}$, i.e., the shaded areas in Figure 8. For the conservative scenario of visibility, the cumulative probability that an eruption exceeds the

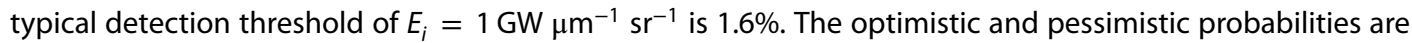
$39 \%$ and $1.4 \times 10^{-5} \%$, respectively.

Figure 8 shows that a detectable eruption is likely visible close to 1 day in the conservative case, because only the initial phases of peak effusion rate [Wadge, 1981] reach a sufficient brightness. We assume that the VIRTIS binning time interval of $t_{\mathrm{obs}}=1$ day best describes the likelihood that a sufficiently bright eruption coincides with VIRTIS imaging in this case. In the optimistic case the visible eruption durations are closer to $t_{\mathrm{obs}}=10$ days. This means that the chance of an eruption coinciding with the imaging is greater, but more of the data is redundant (Figure 4) as it would likely detect the same eruption in several images.

At a rate of volcanism $F_{\text {global }}=1 \mathrm{~km}^{3}$ (3 times the rate of intraplate hot spot volcanism on Earth [Crisp, 1984]), the average frequency of eruptions with average volume $\bar{V}=0.066 \mathrm{~km}^{3}$ (the average of the data set of Wadge [1981]) is 15 eruptions per year for the total surface area of Venus, i.e., $D=1 \times 10^{-10} / \mathrm{d} / \mathrm{km}^{2}$. The solution of equation (11) gives a number of $N_{\text {cons }}=0.009$ detected eruptions for the conservative case and assuming a visibility time window of $t_{\mathrm{obs}}=1$ day. If the visible phases of the eruptions are on average 10 times longer $\left(t_{\text {obs }}=10\right.$ days), the redundancy of VIRTIS images leads to an expected number of detections that is only 5 times higher. For the optimistic case with $t_{\mathrm{obs}}=10$ days, the expected number of detected eruptions is $N_{\text {opt }}=0.7$. With $t_{\text {obs }}=1$ day, this reduces to 0.14 detected eruptions. The pessimistic case gives expected numbers of detected events on the order of $N_{\text {pess }}=10^{-5}$ at $t_{\mathrm{obs}}=1$ day.

\subsection{Constraint on Volcanism Limited to Hot Spots}

Areas outside of hot spot regions comparably covered by VIRTIS show much less thermal emission anomalies. It is possible that volcanic activity is currently confined to active hot spot regions, including the possible hot spot Lada Terra. In this case the spatial distribution of VIRTIS images becomes relevant. This distribution is shown in Figure 9 with the approximate location of hot spot regions. Each image is assumed to monitor volcanic activity for 1 day and thus only the first image per day is counted.

The images cover the hot spots of the southern hemisphere comparatively well over the course of the 836 day period of VIRTIS science observations: Dione Regio is monitored on 57 days, Themis Regio on 79 days, Imdr Regio on 48 days, and Lada Terra on 75 days. Assuming a rate of volcanism of $1 \mathrm{~km}^{3} / \mathrm{yr}$ and again an average eruption volume of $0.066 \mathrm{~km}^{3}$ leads to an average frequency of 0.04 eruptions per day distributed over 10 hot spots. Thus, the expected number of eruptions occurring within the VIRTIS field of view imaging the four hot spots is approximately one. Again, assuming the chances that an eruption is detectable of $1.6 \%$ in the conservative case and $39 \%$ in the optimistic case, leads to the expected numbers of detections of 0.016 and 0.39 , respectively.

In comparison with the expected numbers for uniformly distributed volcanism, i.e., 0.009 detections conservative, 0.14 detections optimistic, the chances to detect eruptions with VIRTIS are somewhat better if the volcanism was confined to hot spot regions. However, these expectation values are difficult to translate into a probability to observe zero eruptions. If only four volcanic centers are monitored, the probability that all are in repose during the short period of observations is not negligible [e.g., Lorenz, 2015]. 


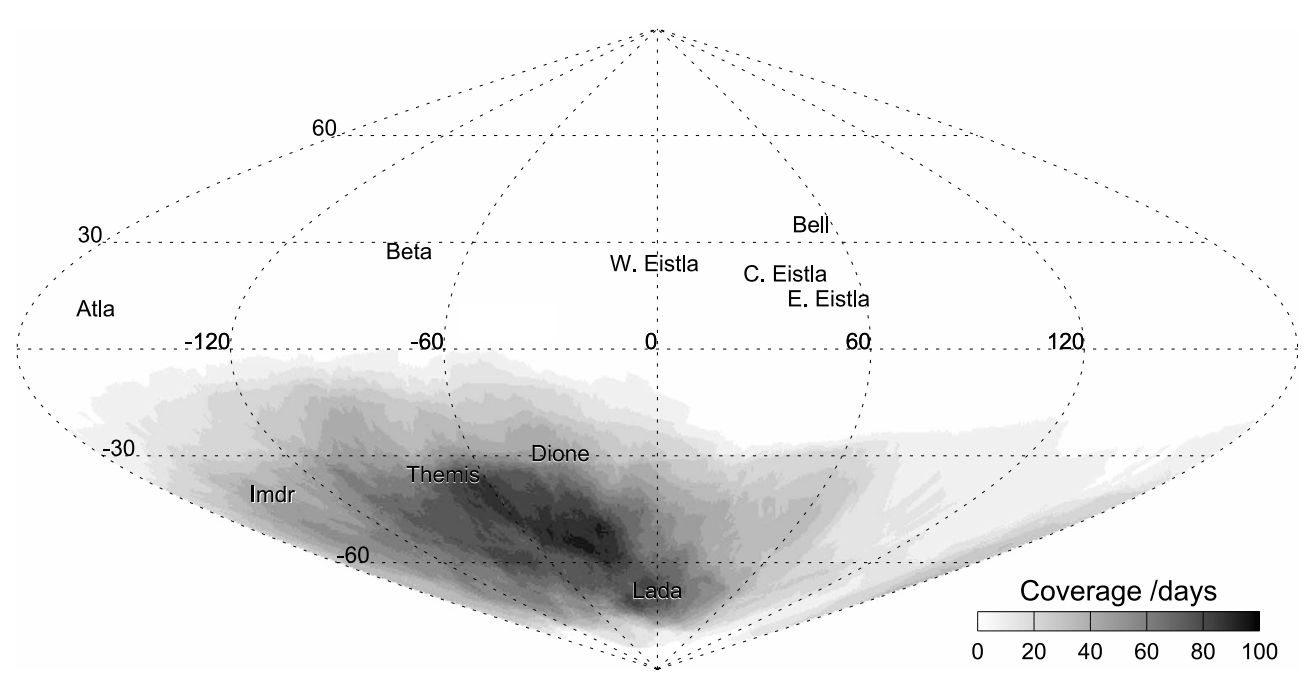

Figure 9. Map showing the number of days VIRTIS monitored the surface of Venus with the approximate locations of the proposed hot spot regions.

\subsection{Constraint on Widely Distributed Volcanism}

If there are many potentially active volcanic centers distributed over the surface of Venus, the possibility that all are in repose becomes insignificant. In this case each surface element can be assigned the same small, independent probability of erupting with sufficient intensity to be observable. The probability of observing a certain number of eruptions can then be described by a Poisson distribution determined by the expected number of observed eruptions.

The probability $P$ to detect $k$ eruptions when given an expected number of detected eruptions $N$ is then

$$
P=\frac{N^{k} e^{-N}}{k !}
$$

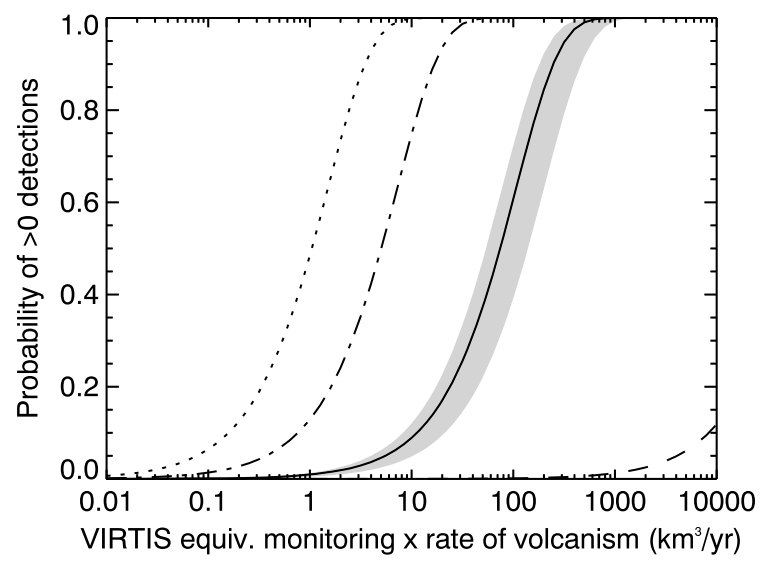

Figure 10. Probability to detect at least one eruption for various assumptions on volcanic style. The expected number of detections increases with greater global rates of volcanism but also with more data similar to the VIRTIS data set, approximately equivalent to monitoring the whole planet for 6 days at a SNR of 16 . The solid line represents our conservative estimate on volcanic style. The grey area indicates the confidence interval due to the search algorithm, i.e., the chance of false negatives and positives below our nominal detection criterion (see section 4.4). The dashed line represents the most optimistic of estimate lava flow visibility and duration, and the dotted line represents the most pessimistic estimate. The dash-dotted line represents a data set with the same coverage as VIRTIS but 20 times better SNR under conservative assumptions on flow brightness.
We assume that the expected number of detected eruptions increases in proportion to the global rate of volcanism and the amount of monitoring. The resulting probabilities to detect at least one eruption (i.e., not zero) are presented in Figure 10. The solid line corresponds to the expected value of $N_{\text {opt }}=0.009$ expected eruptions at a rate of volcanism of $1 \mathrm{~km}^{3} / \mathrm{yr}$.

The search for eruptions has a confidence interval as there might be false negatives or positives below the assumed detection criterion. This can be estimated by scaling the excess thermal emission $E_{i}$ in equation (11) to higher and lower values corresponding to the modified detection criteria that would likely exclude false negatives at $\sigma \sigma$ and still allow for a significant fraction of detection at $3 \sigma$ of noise. As the $E_{i}$ correspond to $4 \sigma$, the scaling is done by a factor of $6 / 4$ and $3 / 4$, respectively. This is represented in Figure 10 by the grey area around the solid line.

This probability based on the conservative assumptions indicates that there is a high likelihood (0.95) of detecting at least one 


\begin{tabular}{|c|c|c|c|}
\hline Anomaly & Dimension $(\mathrm{km})$ & Thermal Emission (GW $\mu \mathrm{m}^{-1} \mathrm{sr}^{-1}$ ) & Eruption Rate $\left(\mathrm{m}^{3} / \mathrm{s}\right)$ \\
\hline A, Orbit 795 & 100 & 0.7 & $26-590$ \\
\hline B, Orbit 1148 & 200 & 0.3 & $11-250$ \\
\hline D, Orbit 1148 & 250 & 0.8 & $30-670$ \\
\hline
\end{tabular}

eruption in the VIRTIS data set, if the rate of volcanism is $>300 \mathrm{~km}^{3} / \mathrm{yr}$. If the VIRTIS data set had 100 times more coverage at the same quality, or less additional coverage and a better chance of detecting eruptions, an eruption would have very likely been observed at a rate of volcanism of $3 \mathrm{~km}^{3} / \mathrm{yr}$.

No detection of an eruption in the VIRTIS data set is consistent with all other estimates of the rate of volcanism (see section 2.1). Even assuming that all radiogenic heat is removed from the mantle only by magma, i.e., a volume of $200 \mathrm{~km}^{3} / \mathrm{yr}$ [Turcotte, 1989], and assuming an intrusive to extrusive ratio of 5:1 [Crisp, 1984] the resulting $40 \mathrm{~km}^{3} / \mathrm{yr}$ of extrusive volcanism still has a $60 \%$ chance to be missed by VIRTIS.

There is an additional uncertainty from the modeling of the thermal emission and style of volcanism. The chance to detect at least one eruption in the VIRTIS data set at $1 \mathrm{~km}^{3} / \mathrm{yr}$ is already $50 \%$ if we use our most optimistic assumptions on the brightness of lava flows plotted as the dashed line in Figure 10. This cannot be used to place an upper limit on the rate of volcanism from the absence of detections. The pessimistic estimate would be more suitable but the dotted line in Figure 10 shows that this is not feasible unless monitoring at VIRTIS SNR was several orders of magnitude more extensive. Even then the uncertainty about our assumptions on the style of volcanism would remain, i.e., if the global rate of volcanism is distributed over frequent eruptions, which however have to be large and intense enough to be detected. Thus, it is very difficult to draw any conclusion without seeing any eruptions.

However, an improvement of the VIRTIS SNR of 16 by a factor of 20 would enable an instrument to see $34 \%$ instead of $1.6 \%$. A new imaging data set that has the same monitoring coverage and as VIRTIS-equivalent to the whole planet for 6 days - but a 20 times higher SNR would have a high likelihood (>75\%) of observing at least one eruption at rates of volcanism of $10 \mathrm{~km}^{3} / \mathrm{yr}$ with conservative assumptions on flow brightness (dash dotted line in Figure 10). This is a rate of volcanism that is consistent with the existing cratering record [Romeo and Turcotte, 2010], more so if the surface of Venus is much younger than previously thought [Bottke et al., 2016].

\section{Discussion}

\subsection{Application to VMC Observations}

The VIRTIS data set does not show any clear signatures of active eruptions, and this does not place a meaningful constraint on the rate of active volcanism on Venus. Shalygin et al. [2015] report transient bright spots in VMC images at Ganis Chasma, north of the center of the Atla regio hot spot (Figure 9). They interpret these spots as three active volcanic eruptions, two of which last at least for 2 days. Our model allows us to translate the anomaly parameters given in the supporting information in the work of Shalygin et al. [2015] into lava eruption rates. In agreement with statements by Shalygin et al. [2015], these rates given in Table 3 are not outside of the range of historically observed eruptions on Earth (compare Figure 8).

Under optimistic assumptions on the visibility of lava flows, the required rates on the order of $10 \mathrm{~m} / \mathrm{s}^{3}$ and not very unusual compared to Earth rates [Wadge, 1981; Harris et al., 2011]. Under conservative assumptions, these anomalies require relatively large though not unprecedented eruption rates on the order of hundreds of cubic meters per second. The volumes corresponding to the conservative rates over 2 days are on the order of $0.1 \mathrm{~km}^{3}$. Clearly, if the anomalies observed by VMC within 1 year are indeed eruptions, this indicates that significant volcanic activity is ongoing.

The constraint on the rate of active volcanism depends on how much of the surface was monitored by VMC how often, and the data presented in the work of Shalygin et al. [2015] are not sufficient for an estimate. Assuming for comparison that the monitoring capability of VMC is the same as that of VIRTIS, and assuming that the volcanism can be represented by a Poisson distribution (equation (23)) leads to the rates of volcanism that 
have the highest likelihood of resulting in the number of reported eruptions. This is a rate of $4.5 \mathrm{~km}^{3} / \mathrm{yr}$ for the optimistic scenario of visibility, and $350 \mathrm{~km}^{3} / \mathrm{yr}$ for the conservative scenario.

A rate of $4.5 \mathrm{~km}^{3} / \mathrm{yr}$ is consistent with crater retention ages; however, this requires that the thermal renewal of flow surfaces on Venus are on average similar to that of eruptions with lava fountains on Earth. Lava fountains might be less frequent on Venus because the high surface pressure reduces gas exsolution, that is, one of the drivers of fountains on Earth [Head and Wilson, 1986].

This estimate depends on the assumption that VMC has a similar monitoring capability as VIRTIS. Unlike VIRTIS, VMC lacks a band for stray light and atmospheric corrections and can only observe when the spacecraft is in the shadow of the planet. Shalygin et al. [2015] further select only images with unusually high background radiance (1.5 times of the average) in the assumption that this is due to higher atmospheric transmittance. These limitations are offset to some uncertain extent by the wider field of view of VMC and its longer duration of operations. The fact that two of three events occur on the same day hints that a Poisson process might not be a good representation of the cause of these anomalies.

Shalygin et al. [2015] point out that the location of their anomalies is among the stratigraphically youngest regions of the planet based on the work of Ivanov and Head [2011, 2013], thus the abundance of thermal anomalies at Ganis Chasma compared to the southern hemisphere observed by VIRTIS might just be a result of a concentration of volcanism in this region. As described by Shalygin et al. [2015], the anomalies seen in orbit 1148 cannot be attributed to a contiguous area at brightness temperatures between 800 and $1100 \mathrm{~km}$. The hot areas would have to be distributed over a distance of at least $200 \mathrm{~km}$. This is a large area for eruptions that are only visible for 2 days. It seems unlikely that a flow field with a dimension of $200 \mathrm{~km}$ has been built from a single vent in such short time, even at the high effusion rates corresponding to the conservative visibility estimate. Another possibility might be a fissure eruption. Head and Wilson [1986] give a minimum number for effusion rate per length of a fissure of approximately $3.7 \mathrm{~m} / \mathrm{s} / \mathrm{km}$ for Venus; therefore, an interpretation of the $200 \mathrm{~km}$ long thermal anomalies [Shalygin et al., 2015] as fissure eruptions is roughly consistent with our conservative estimate of the required effusion rates, but leans toward higher values.

These rates are already very high compared to terrestrial eruptions; therefore, the hypothesis that two of such eruptions occur on the same day seems like an unlikely coincidence. Shalygin et al. [2015] discuss the possibility of false positives from uncorrected atmospheric variability and incorrect background correction due to misaligned IR imaging and radar altimetry in their supporting information but reject these possibilities without giving a confidence level. The amplitude of the reported anomalies $(20 \%-30 \%)$ is within 3 standard deviations of the orbit to orbit atmospheric variability in VMC images, reported as 14\% [Shalygin et al., 2015]. Shalygin et al. [2015] state that the anomalies interpreted as eruptions are distinct from atmospheric anomalies because they are at the same location on several orbits. The locations of the anomalies have in common that they are located at topographic highs on the rift flank. The anomalies themselves correspond to less than three Kelvin brightness temperature difference to the expected brightness temperature based on the assumption of a temperature lapse rate of $8.1 \mathrm{~K} / \mathrm{km}$ and an atmospheric model. In the images of the supporting information, the topographic low of the rift seems to be correlated with 10-20\% lower than expected radiance values. This raises the possibility that the reported anomalies are simply an artifact of an incorrect background correction.

All in all we think that there is a significant risk of false positives in the interpretation of VMC images by Shalygin et al. [2015]. The positives reported by Shalygin et al. [2015] would likely not have exceeded our significance threshold of 4 standard deviations of residual noise. The interpretation favored by Shalygin et al. [2015], on the other hand, involves two in comparison with Earth volcanism's very unusual eruptions coinciding with the same VMC imaging swath and therefore an event that seems to have a low probability.

\subsection{Lava Flow Model Uncertainty}

The estimate which fraction of eruptions is detectable has large uncertainties due to the parameters used for modeling the thermal emission of lava flows. Our assumptions already encompass a wide parameter space, but we do not have values for probability distribution and covariance of these parameters. One large contribution to the uncertainty from the model is the heat flux from convection. If the forced convection heat flux coefficient derived by Keszthelyi et al. [2003] scales proportional to atmospheric density, heat capacity and wind speed, convective heat flux is 4 times higher than that on Earth. The coupling of radiative and 
convective cooling also occurs in the presence of wind, but the reduction in total heat flow is less [Snyder, 2002]; thus, higher effusion rates are required for detection, possibly depending on flow geometry [Head and Wilson, 1986].

\subsection{Uncertainty Due to the Style of Volcanism}

The other large uncertainty in the constraint of the rate of volcanism is the likelihood of sufficiently high eruption rates and volumes, and the question of the typical lava flow surface texture on Venus. The surface panoramas of the Venera landers show a surface resembling pahoehoe surfaces or talus slopes [Garvin et al., 1984]. The radar properties of many large lava flows on the surface of Venus are consistent with a pahoehoe texture [Campbell and Campbell, 1992; Kratter et al., 2007] although aa is expected for high effusion rate flows. Head and Wilson [1986] state that aa texture should form sooner on Venus because of the more rapid crust formation due to the higher convective heat loss. To reconcile this with their observations Campbell and Campbell [1992] hypothesize that weathering smoothes aa flows to resemble pahoehoe. On the other hand, a lower convective and radiative heat flux from the flows as modeled by Snyder [2002] might favor a pahoehoe flow texture. In this case lava flows on Venus might be very hard to detect, because of the low effective brightness temperature of pahoehoe flows. There is at least some indication of nonpahoehoe texture in the fractal dimension of some flow outlines on Venus [Bruno et al., 1992].

Another question is how frequent eruptions are on Venus, which at a given rate of volcanism is inversely proportional to the average volume. Phillips et al. [1992] show that the number of craters and fraction of modified craters may be consistent with a constant average global rate of volcanism of $1 \mathrm{~km}^{3} / \mathrm{yr}$ if resurfacing occurs in patches with average diameters of $400 \mathrm{~km}$. The frequency of such resurfacing events consistent with the crater frequency is only one per approximately 150,000 years. However, the constraint on the duration of these events is only that is must be short compared to the crater retention age of 0.4-1 Ga [Herrick et al., 1997] in order to retain the observed number of volcanically modified craters. The duration of activity of terrestrial continental flood basalt regions is on the order of several million years [White et al., 2006]. If the duration of the resurfacing events in the context of the Phillips et al. [1992] model are of the same order of magnitude, there could be several active regions at any time. The probability to detect activity in these regions then depends on the frequency of individual eruptions.

Bondarenko et al. [2010] interpret Magellan measurements of anomalous radiothermal emission from a vast area $\left(>40,000 \mathrm{~km}^{2}\right)$ of plains in Bereghinia Planitia as evidence for emplacement within the last 100 years. This would indicate that plains resurfacing is ongoing and that eruptions are large. The flows at Bereghinia are at least $30 \mathrm{~m}$ thick [Bondarenko et al., 2010] and thus the volume of the eruption would have been $>1200 \mathrm{~km}^{3}$. At the rate for equilibrium resurfacing of $1 \mathrm{~km}^{3} / \mathrm{yr}$ [Phillips et al., 1992], such eruptions would occur on average once per millennium.

Even if the eruptions are frequent and voluminous enough to have a significant chance of detection, the effusion rate might be still too low. It is thought that the area of single flow lobes scales with the effusion rate of the eruptions [Crisp and Baloga, 1990b]. Several studies of Magellan radar images have pointed out the large area of single flow lobes on Venus and explained this with high effusion rates based on analogy with Earth flows [e.g., Roberts et al., 1992; Stofan et al., 2001].

However, these observations might not provide a representative distribution of effusion rate values because of observational bias of Magellan imaging data. The most frequent effusive eruptions on Earth feed flows lobes reaching a few square kilometers. Such small features can be identified at the full resolution of the Magellan radar imaging (100 m) [Pettengill et al., 1991], but the interpretation is often ambiguous [Grindrod et al., 2010]. In particular, it is difficult to trace the boundaries of single flow lobes within a flow field with relatively uniform surface roughness.

\subsection{Statistical Approach Uncertainty}

Our approach of calculating the thermal emission of lava flows as constant at the average for discrete assumed values of eruption durations, the assumption of an eruption volume distribution, and the modeling of eruption detection probability from a Poisson distribution is somewhat simplistic. The uncertainty arising from this is most likely small compared to the other sources of uncertainty, and at this point a better approach would certainly not provide more insight. 


\section{Conclusions}

We have searched the VIRTIS on Venus Express data set of nightside thermal emission at $1.02 \mu \mathrm{m}$ for the signatures of active eruptions. VIRTIS would have been able to identify eruptions with an area-integrated

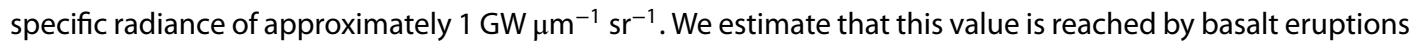
with an effusion rate of approximately $1000 \mathrm{~m}^{3} / \mathrm{s}$, provided that such eruptions form flows with a surface age distribution comparable to that of aa flows observed by Wright et al. [2011].

We did not detect any clear eruptions signature. Using surface temperature distributions from Earth lava flows [Wright et al., 2011], a model for lava flow surface cooling, and an eruption rate and duration probability distribution modeled on Earth data [Wadge, 1981], we estimate that we would have detected at least one eruption with a high likelihood, if the global rate of volcanism exceeds $300 \mathrm{~km}^{3} / \mathrm{yr}$. This is consistent with all estimates of the rate of volcanism [Fegley and Prinn, 1989; Schaber et al., 1992; Phillips et al., 1992; Romeo and Turcotte, 2010; Ivanov and Head, 2013] and thus provides no new constraints or insights.

The transient bright spots in VMC images [Shalygin et al., 2015] can be interpreted with our thermal emission model and the interpretation as volcanism indicates a very high frequency of very high effusion rate eruption in the Ganis Chasma region. This high frequency points toward the higher global rate of volcanism of constant resurfacing, but this is very uncertain since the description of the VMC data set in the work of Shalygin et al. [2015] is not sufficient to estimate the monitoring capability. Although this possibility has been rejected by Shalygin et al. [2015], false positives cannot be excluded with complete certainty and might be more likely than the hypothesis that the anomalies are indeed eruptions.

In addition to the insufficient observation capability of Venus Express, there are large uncertainties due to the modeling of lava flows and the unknown style of volcanism on Venus. Pahoehoe flow texture might be dominant on Venus and such flows might be very difficult to detect. The uncertainty can be reduced by decreasing the volume of the lava flow parameter space under consideration, e.g., by observing lava flow thickness with highly resolved altimetry [Smrekar et al., 2016] or by studying parameter correlations, e.g., lava flow crust fractures as function of effusion rate and flow thickness, and by better modeling of the cooling in the infrared opaque atmosphere of Venus in the presence of wind [Snyder, 2002].

The main obstacle in the search for active volcanism is however the low signal-to-noise ratio of the imaging instruments of Venus Express. The VIRTIS spectrometer is a flight spare from the Rosetta mission, and it was not optimized to observe the nightside of Venus at $1 \mu \mathrm{m}$. Improved signal-to-noise ratio could detect less intense eruptions, because the signature is proportional to effusion rate. Thus, increasing the signal-to-noise ratio from 16 (VIRTIS) by a technically feasible factor of 20 [Helbert et al., 2016], could possibly detect flows with $50 \mathrm{~m}^{3} / \mathrm{s}$, a value more frequently achieved by Earth eruptions. A low polar orbit as is optimal for radar mapping [Smrekar et al., 2016] would allow multiple observation of the same surface per day, greatly increasing the reliability of any detection.

Future observations would ideally have spectral bands observing atmospheric thermal emission to correct for cloud variability, and ideally more bands observing surface thermal emission in the range between 0.85 and $1.18 \mu \mathrm{m}$, which would allow color temperature estimates [Hashimoto and Imamura, 2001]. The infrared cameras on board the spacecraft Akatsuki [Nakamura et al., 2011] have this spectral capability. Akatsuki was recently inserted into Venus orbit, albeit with a greater apocenter distance than originally planned.

In addition to searching for active flows, future Venus missions could employ a variety of methods to detect recent flows. A new IR spectrometer [Helbert et al., 2016] could look for unweathered basalts [Smrekar et al., 2010] globally, including potential changes since Venus Express and Akatsuki. Repeat observations of high-resolution radar altimetry could reveal new flow, repeat radar images could detect new flows if they have significantly different radar brightness than underlying flows [Lorenz, 2015].

\section{References}

Allen, D. A., and J. W. Crawford (1984), Cloud structure on the dark side of Venus, Nature, 307, 222-224.

Armann, M., and P. J. Tackley (2012), Simulating the thermochemical magmatic and tectonic evolution of Venus's mantle and lithosphere: Two-dimensional models, J. Geophys. Res., 117, E12003, doi:10.1029/2012JE004231.

Avduevskij, V. S., V. S. Avduevsky, M. Y. Marov, M. K. Rozhdestvenskij, M. K. Rozhdestvensky, N. F. Borodin, and V. V. Kerzhanovich (1971), Soft landing of Venera 7 on the Venus surface and preliminary results of investigations of the Venus atmosphere., J. Atmos. Sci., 28, 263-269, doi:10.1175/1520-0469(1971)028<0263:SLOVOT>2.0.CO;2. 
Basilevsky, A. T. (1993), Age of rifting and associated volcanism in Atla Regio, Venus, Geophys. Res. Lett., 20, 883-886, doi:10.1029/93GL00736.

Bézard, B., C. C. C. Tsang, R. W. Carlson, G. Piccioni, E. Marcq, and P. Drossart (2009), Water vapor abundance near the surface of Venus from Venus Express/VIRTIS observations, J. Geophys. Res., 114, E00B39, doi:10.1029/2008JE003251.

Bondarenko, N. V., J. W. Head, and M. A. Ivanov (2010), Present-day volcanism on Venus: Evidence from microwave radiometry, Geophys. Res. Lett., 37, L23202, doi:10.1029/2010GL045233.

Bottke, W. F., D. Vokrouhlicky, B. Ghent, S. Mazrouei, S. Robbins, and S. Marchi (2016), On asteroid impacts, crater scaling laws, and a proposed younger surface age for Venus, in Proceedings of the 47th Lunar and Planetary Science Conference, 2036 pp., LPI Contribution No. 1903, Woodlands, Tex.

Bridges, N. T. (1997), Ambient effects on basalt and rhyolite lavas under Venusian, subaerial, and subaqueous conditions, J. Geophys. Res., 102, 9243-9256, doi:10.1029/97JE00390.

Bruno, B. C., G. J. Taylor, S. K. Rowland, P. G. Lucey, and S. Self (1992), Lava flows are fractals, Geophys. Res. Lett., 19, 305-308, doi:10.1029/91GL03039.

Campbell, B. A., and D. B. Campbell (1992), Analysis of volcanic surface morphology on Venus from comparison of Arecibo, Magellan, and terrestrial airborne radar data, J. Geophys. Res., 97, 16,293-16,314.

Crisp, J. (1984), Rates of magma emplacement and volcanic output, J. Volcanol. Geotherm. Res., 20, 177-211, doi:10.1016/0377-0273(84)90039-8.

Crisp, J., and S. Baloga (1990a), A model for lava flows with two thermal components, J. Geophys. Res., 95, 1255-1270, doi:10.1029/JB095iB02p01255.

Crisp, J., and S. Baloga (1990b), A method for estimating eruption rates of planetary lava flows, Icarus, 85, 512-515, doi:10.1016/0019-1035(90)90129-W.

Davies, A. G. (1996), lo's volcanism: Thermo-physical models of silicate lava compared with observations of thermal emission, Icarus, 124, 45-61, doi:10.1006/icar.1996.0189.

Davies, A. G. (2003), Volcanism on lo: Estimation of eruption parameters from Galileo NIMS data, J. Geophys. Res., 108, 5106, doi:10.1029/2001JE001509.

Esposito, L. W. (1984), Sulfur dioxide-Episodic injection shows evidence for active Venus volcanism, Science, 223, 1072-1074, doi:10.1126/science.223.4640.1072.

Fegley, B., and R. G. Prinn (1989), Estimation of the rate of volcanism on Venus from reaction rate measurements, Nature, 337, 55-58, doi: $10.1038 / 337055 \mathrm{a} 0$.

Fegley, B., A. H. Treiman, and V. L. Sharpton (1992), Venus surface mineralogy-Observational and theoretical constraints, in Lunar and Planetary Science Conference Proceedings, vol. 22, edited by G. Ryder and V. L. Sharpton, pp. 3-20, Lunar and Planetary Institute, Houston, Tex.

Fegley, B., Jr., G. Klingelhoefer, R. A. Brackett, N. Izenberg, D. T. Kremser, and K. Lodders (1995a), Basalt oxidation and the formation of hematite on the surface of Venus, Icarus, 118, 373-383, doi:10.1006/icar.1995.1197.

Fegley, B., Jr., K. Lodders, A. H. Treiman, and G. Klingelhoefer (1995b), The rate of pyrite decomposition on the surface of Venus, Icarus, 115 , 159-180, doi:10.1006/icar.1995.1086.

Ford, P. G., and G. H. Pettengill (1992), Venus topography and kilometer-scale slopes, J. Geophys. Res., 97, 13,103-13,114.

Garvin, J. B., J. W. Head, M. T. Zuber, and P. Helfenstein (1984), Venus - The nature of the surface from Venera panoramas, J. Geophys. Res., 89, 3381 -3399, doi:10.1029/JB089iB05p03381.

Griffiths, R. W., and J. H. Fink (1992), The morphology of lava flows in planetary environments - Predictions from analog experiments, J. Geophys. Res., 97, 19,739-19,748, doi:10.1029/92JB01953.

Grindrod, P. M., E. R. Stofan, and J. E. Guest (2010), Volcanism and resurfacing on Venus at the full resolution of Magellan SAR data, Geophys. Res. Lett., 37, L15201, doi:10.1029/2010GL043424.

Grinspoon, D. H., J. B. Pollack, B. R. Sitton, R. W. Carlson, L. W. Kamp, K. H. Baines, T. Encrenaz, and F. W. Taylor (1993), Probing Venus's cloud structure with Galileo NIMS, Planet. Space Sci., 41, 515-542, doi:10.1016/0032-0633(93)90034-Y.

Guest, J. E., M. H. Bulmer, J. Aubele, K. Beratan, R. Greeley, J. W. Head, G. Michaels, C. Weitz, and C. Wiles (1992), Small volcanic edifices and volcanism in the plains of Venus, J. Geophys. Res., 97, 15,949-15,966.

Global Volcanism Network (GVN) (1991), Etna, Smithson. Inst. Bull. Global Volcan. Network, 16(12), 2-3.

Global Volcanism Network (GVN) (1992), Etna, Smithson. Inst. Bull. Global Volcan. Network, 17(2), $12-16$.

Global Volcanism Network (GVN) (1993), Etna, Smithson. Inst. Bull. Global Volcan. Network, 18(2), 12-13.

Harris, A., A. Steffke, S. Calvari, and L. Spampinato (2011), Thirty years of satellite-derived lava discharge rates at Etna: Implications for steady volumetric output, J. Geophys. Res., 116, B08204, doi:10.1029/2011JB008237.

Harris, A. J. L., S. Blake, D. A. Rothery, and N. F. Stevens (1997), A chronology of the 1991 to 1993 Mount Etna eruption using advanced very high resolution radiometer data: Implications for real-time thermal volcano monitoring, J. Geophys. Res., 102, 7985-8004, doi:10.1029/96JB03388.

Harris, A. J. L., L. P. Flynn, L. Keszthelyi, P. J. Mouginis-Mark, S. K. Rowland, and J. A. Resing (1998), Calculation of lava effusion rates from Landsat TM data, Bull. Volcanol., 60, 52-71, doi:10.1007/s004450050216.

Harris, A. J. L., J. B. Murray, S. E. Aries, M. A. Davies, L. P. Flynn, M. J. Wooster, R. Wright, and D. A. Rothery (2000), Effusion rate trends at Etna and Krafla and their implications for eruptive mechanisms, J. Volcanol. Geotherm. Res., 102(3-4), 237-269, doi:10.1016/S0377-0273(00)00190-6.

Hashimoto, G. L., and Y. Abe (2005), Climate control on Venus: Comparison of the carbonate and pyrite models, Planet. Space Sci., 53, 839-848, doi:10.1016/j.pss.2005.01.005.

Hashimoto, G. L., and T. Imamura (2001), Elucidating the rate of volcanism on Venus: Detection of lava eruptions using near-infrared observations, Icarus, 154, 239-243, doi:10.1006/icar.2001.6713.

Hashimoto, G. L., and S. Sugita (2003), On observing the compositional variability of the surface of Venus using nightside near-infrared thermal radiation, J. Geophys. Res., 108, 13-18, doi:10.1029/2003JE002082.

Hauck, S. A., R. J. Phillips, and M. H. Price (1998), Venus: Crater distribution and plains resurfacing models, J. Geophys. Res., 103, 13,635-13,642, doi:10.1029/98JE00400.

Head, J. W., L. S. Crumpler, J. C. Aubele, J. E. Guest, and R. S. Saunders (1992a), Venus volcanism —Classification of volcanic features and structures, associations, and global distribution from Magellan data, J. Geophys. Res., 97, 13,153-13,197.

Head, J. W., III, and L. Wilson (1986), Volcanic processes and landforms on Venus - Theory, predictions, and observations, J. Geophys. Res., 91, 9407-9446, doi:10.1029/JB091iB09p09407. 
Head, J. W., III, E. M. Parmentier, and P. C. Hess (1992b), Chemical differentiation on one-plate planets: Predictions and geologic observations for Venus, in Lunar and Planetary Inst., Papers Presented to the International Colloquium on Venus, pp. 45-47, LPI Contributions No. 789 , US.

Helbert, J., and A. Maturilli (2009), The emissivity of a fine-grained labradorite sample at typical Mercury dayside temperatures, Earth Planet. Sci. Lett., 285, 347-354, doi:10.1016/j.epsl.2009.02.031.

Helbert, J., et al. (2016), The Venus Emissivity Mapper (VEM) concept, Infrared Remote Sensing and Instrumentation XXIV, SPIE, San Diego, Calif., doi:10.1117/12.2237568.

Helbert, J., A. Maturilli, M. D. Dyar, S. Ferrari, N. Mueller, and S. Smrekar (2017), First set of laboratory Venus analog spectra for all atmospheric windows, in Proceedings of the 48th Lunar and Planetary Science Conference, 1512 pp., LPI Contribution No. 1964, The Woodlands, Tex.

Herrick, R. R., V. L. Sharpton, M. C. Malin, S. N. Lyons, and K. Feely (1997), Morphology and morphometry of impact craters, in Venus II: Geology, Geophysics, Atmosphere, and Solar Wind Environment, edited by S. W. Bougher, D. M. Hunten, and R. J. Phillips, pp. 1015-1046, Univ. of Arizona Press, Tucson.

Hon, K., J. Kauahikaua, R. Denlinger, and K. Mackay (1994a), Emplacement and inflation of pahoehoe sheet flows: Observations and measurements of active lava flows on Kilauea Volcano, Hawaii, Geol. Soc. Am. Bull., 106(3), 351-370, doi:10.1130/0016-7606(1994)106<0351:EAIOPS>2.3.CO;2.

Hon, K., J. P. Kauahikaua, and K. Mackay (1994b), Inflation and cooling data from pahoehoe sheet flows on Kilauea Volcano, U.S. Geol. Surv. Open File Rep., 93-342-A.

Ivanov, M. A., and J. W. Head (2010), The Lada Terra rise and Quetzalpetlatl Corona: A region of long-lived mantle upwelling and recent volcanic activity on Venus, Planet. Space Sci., 58, 1880-1894, doi:10.1016/j.pss.2010.08.018.

Ivanov, M. A., and J. W. Head (2011), Global geological map of Venus, Planet. Space Sci., 59, 1559-1600, doi:10.1016/j.pss.2011.07.008

Ivanov, M. A., and J. W. Head (2013), The history of volcanism on Venus, Planet. Space Sci., 84, 66-92, doi:10.1016/j.pss.2013.04.018.

Ivanov, M. A., and J. W. Head (2015), Volcanically embayed craters on Venus: Testing the catastrophic and equilibrium resurfacing models, Planet. Space Sci., 106, 116-121, doi:10.1016/j.pss.2014.12.004.

Kappel, D., G. Arnold, R. Haus, G. Piccioni, and P. Drossart (2012), Refinements in the data analysis of VIRTIS-M-IR Venus nightside spectra, Adv. Space Res., 50, 228-255, doi:10.1016/j.asr.2012.03.029.

Kappel, D., R. Haus, and G. Arnold (2015), Error analysis for retrieval of Venus' IR surface emissivity from VIRTIS/VEX measurements, Planet. Space Sci., 113, 49-65, doi:10.1016/j.pss.2015.01.014.

Kaula, W. M., and R. J. Phillips (1981), Quantitative tests for plate tectonics on Venus, Geophys. Res. Lett., 8, 1187-1190.

Keszthelyi, L., and R. Denlinger (1996), The initial cooling of pahoehoe flow lobes, Bull. Volcanol., 58, 5-18, doi:10.1007/s004450050121.

Keszthelyi, L., A. J. L. Harris, and J. Dehn (2003), Observations of the effect of wind on the cooling of active lava flows, Geophys. Res. Lett., 30(19), 1989, doi:10.1029/2003GL017994.

Kratter, K. M., L. M. Carter, and D. B. Campbell (2007), An expanded view of Lada Terra, Venus: New Arecibo radar observations of Quetzalpetlatl Corona and surrounding flows, J. Geophys. Res., 112, E04008, doi:10.1029/2006JE002722.

Lecacheux, J., P. Drossart, P. Laques, F. Deladerriere, and F. Colas (1993), Detection of the surface of Venus at 1.0 micrometer from ground-based observations, Planet. Space Sci., 41, 543-549, doi:10.1016/0032-0633(93)90035-Z.

Lorenz, R. D. (2015), Probabilistic constraints from existing and future radar imaging on volcanic activity on Venus, Planet. Space Sci., 117, 356-361, doi:10.1016/j.pss.2015.07.009.

Lorenz, R. D. (2016), Surface winds on Venus: Probability distribution from in-situ measurements, Icarus, 264, 311-315, doi:10.1016/j.icarus.2015.09.036.

Malin, M. C. (1980), Lengths of Hawaiian lava flows, Geology, 8(7), 306-308, doi:10.1130/0091-7613(1980)8<306:LOHLF>2.0.CO;2.

Marcq, E., J.-L. Bertaux, F. Montmessin, and D. Belyaev (2013), Variations of sulphur dioxide at the cloud top of Venus' dynamic atmosphere, Nat. Geosci., 6, 25-28, doi:10.1038/ngeo1650.

Markiewicz, W. J., et al. (2007), Venus monitoring camera for Venus Express, Planet. Space Sci., 55, 1701-1711, doi:10.1016/j.pss.2007.01.004.

Marov, M. Y., V. S. Avduevsky, N. F. Borodin, A. P. Ekonomov, V. V. Kerzhanovich, V. P. Lysov, B. Y. Moshkin, M. K. Rozhdestvensky, and O. L. Ryabov (1973), Preliminary results on the Venus atmosphere from the Venera 8 Descent Module, Icarus, 20, 407-421, doi:10.1016/0019-1035(73)90014-6.

McKinnon, W. B., K. J. Zahnle, B. A. Ivanov, and H. J. Melosh (1997), Cratering on Venus: Models and observations, in Venus II: Geology, Geophysics, Atmosphere, and Solar Wind Environment, edited by S. W. Bougher, D. M. Hunten, and R. J. Philips, pp. 969-1014, Univ. of Arizona Press, Tucson.

Meadows, V. S., and D. Crisp (1996), Ground-based near-infrared observations of the Venus nightside: The thermal structure and water abundance near the surface, J. Geophys. Res., 101, 4595-4622, doi:10.1029/95JE03567.

Mueller, N., J. Helbert, G. L. Hashimoto, C. C. C. Tsang, S. Erard, G. Piccioni, and P. Drossart (2008), Venus surface thermal emission at $1 \mu \mathrm{m}$ in VIRTIS imaging observations: Evidence for variation of crust and mantle differentiation conditions, J. Geophys. Res., 113, E00B17, doi:10.1029/2008JE003118.

Mueller, N., J. Helbert, S. Erard, G. Piccioni, and P. Drossart (2012), Rotation period of Venus estimated from Venus Express VIRTIS images and Magellan altimetry, Icarus, 217(2), 474-483, doi:10.1016/j.icarus.2011.09.026.

Nakamura, M., et al. (2011), Overview of Venus orbiter, Akatsuki, Earth Planets Space, 63, 443-457, doi:10.5047/eps.2011.02.009.

Pettengill, G. H., E. Eliason, P. G. Ford, G. B. Loriot, H. Masursky, and G. E. McGill (1980), Pioneer Venus radar results-Altimetry and surface properties, J. Geophys. Res., 85, 8261-8270, doi:10.1029/JA085iA13p08261.

Pettengill, G. H., P. G. Ford, W. T. K. Johnson, R. K. Raney, and L. A. Soderblom (1991), Magellan—Radar performance and data products, Science, 252, 260-265.

Phillips, R. J., and N. R. Izenberg (1995), Ejecta correlations with spatial crater density and Venus resurfacing history, Geophys. Res. Lett., 22, 1517-1520, doi:10.1029/95GL01412.

Phillips, R. J., R. F. Raubertas, R. E. Arvidson, I. C. Sarkar, R. R. Herrick, N. Izenberg, and R. E. Grimm (1992), Impact craters and Venus resurfacing history, J. Geophys. Res., 97, 15,923-15,948.

Piccioni, G., et al. (2007), VIRTIS (Visible and Infrared Imaging Spectrometer) for Venus Express, 1295, 1-27.

Pieri, D. C., and S. M. Baloga (1986), Eruption rate, area, and length relationships for some Hawaiian lava flows, J. Volcanol. Geotherm. Res., 30, 29-45, doi:10.1016/0377-0273(86)90066-1.

Pieters, C. M., J. W. Head, W. Patterson, S. Pratt, and J. Garvin (1986), The color of the surface of Venus, Science, 234, 1379-1383, doi:10.1126/science.234.4782.1379.

Press, W., S. Teukolsky, W. Vetterling, and B. Flannery (1992), Numerical Recipes in C, 2nd ed., Cambridge Univ. Press, Cambridge, U. K. 
Rappaport, N. J., A. S. Konopliv, A. B. Kucinskas, and P. G. Ford (1999), An improved 360 degree and order model of Venus topography, Icarus, 139, 19-31, doi:10.1006/icar.1999.6081.

Roberts, K. M., J. E. Guest, J. W. Head, and M. G. Lancaster (1992), Mylitta Fluctus, Venus: Rift-related, centralized volcanism and the emplacement of large-volume flow units, J. Geophys. Res., 97, 15,991-16,015.

Romeo, I., and D. L. Turcotte (2010), Resurfacing on Venus, Planet. Space Sci., 58, 1374-1380, doi:10.1016/j.pss.2010.05.022.

Rowland, S. K., and G. P. Walker (1990), Pahoehoe and aa in Hawaii: Volumetric flow rate controls the lava structure, Bull. Volcanol., 52(8), 615-628, doi:10.1007/BF00301212.

Schaber, G. G., R. G. Strom, H. J. Moore, L. A. Soderblom, R. L. Kirk, D. J. Chadwick, D. D. Dawson, L. R. Gaddis, J. M. Boyce, and J. Russell (1992), Geology and distribution of impact craters on Venus-What are they telling us?, J. Geophys. Res., 97, 13,257-13,301.

Seiff, A., J. T. Schofield, A. J. Kliore, F. W. Taylor, and S. S. Limaye (1985), Models of the structure of the atmosphere of Venus from the surface to 100 kilometers altitude, Adv. Space Res., 5, 3-58, doi:10.1016/0273-1177(85)90197-8.

Shalygin, E. V., A. T. Basilevsky, W. J. Markiewicz, D. V. Titov, M. A. Kreslavsky, and T. Roatsch (2012), Search for ongoing volcanic activity on Venus: Case study of Maat Mons, Sapas Mons and Ozza Mons volcanoes, Planet. Space Sci., 73, 294-301, doi:10.1016/j.pss.2012.08.018.

Shalygin, E. V., W. J. Markiewicz, A. T. Basilevsky, D. V. Titov, N. I. Ignatiev, and J. W. Head (2015), Active volcanism on Venus in the Ganiki Chasma rift zone, Geophys. Res. Lett., 42, 4762-4769, doi:10.1002/2015GL064088.

Smrekar, S. E. (1994), Evidence for active hotspots on Venus from analysis of Magellan gravity data, Icarus, 112, 2-26, doi:10.1006/icar.1994.1166.

Smrekar, S. E., and A. Davaille (2015), Possible plume-initiated subduction on Venus: Results from laboratory experiments and corona examples, in Comparative Tectonic and Geodynamics of Venus, Earth and Rocky Exoplanets, 5033 pp., LPI Contribution No. 1839, Pasadena, Calif.

Smrekar, S. E., and R. J. Phillips (1991), Venusian highlands - Geoid to topography ratios and their implications, Earth Planet. Sci. Lett., 107, 582-597, doi:10.1016/0012-821X(91)90103-O.

Smrekar, S. E., E. R. Stofan, N. Mueller, A. Treiman, L. Elkins-Tanton, J. Helbert, G. Piccioni, and P. Drossart (2010), Recent hotspot volcanism on Venus from VIRTIS emissivity data, Science, 328, 605-608, doi:10.1126/science.1186785.

Smrekar, S. E., S. Hensley, M. D. Dyar, J. Helbert, and VERITAS Team (2016), VERITAS (Venus emissivity, radio science, InSAR, topography and spectroscopy): A proposed discovery mission, in Proceedings of the 47th Lunar and Planetary Science Conference, $2439 \mathrm{pp} .$, LPI Contribution No. 1903, The Woodlands, Tex.

Snyder, D. (2002), Cooling of lava flows on Venus: The coupling of radiative and convective heat transfer, J. Geophys. Res., 107, 5080-5088, doi:10.1029/2001JE001501.

Spohn, T. (1991), Mantle differentiation and thermal evolution of Mars, Mercury, and Venus, Icarus, 90, 222-236, doi:10.1016/0019-1035(91)90103-Z.

Stofan, E. R., S. E. Smrekar, D. L. Bindschadler, and D. A. Senske (1995), Large topographic rises on Venus: Implications for mantle upwelling, J. Geophys. Res., 100, 23,317-23,328, doi:10.1029/95JE01834.

Stofan, E. R., J. E. Guest, and D. L. Copp (2001), Development of large volcanoes on Venus: Constraints from Sif, Gula, and Kunapipi Montes, Icarus, 152, 75-95, doi:10.1006/icar.2001.6633.

Stofan, E. R., A. W. Brian, and J. E. Guest (2005), Resurfacing styles and rates on Venus: Assessment of 18 Venusian quadrangles, Icarus, 173 , 312-321, doi:10.1016/j.icarus.2004.08.004.

Stone, P. H. (1975), The dynamics of the atmosphere of Venus, J. Atmos. Sci., 32, 1005-1016.

Strom, R. G., G. G. Schaber, and D. D. Dawsow (1994), The global resurfacing of Venus, J. Geophys. Res., 99, 10,899-10,926.

Surkov, I. A. (1983), Studies of Venus rocks by Veneras 8, 9, and 10, in Venus, pp. 154-158, Univ. of Arizona Press, Tucson.

Surkov, I. A., L. P. Moskaleva, V. P. Khariukova, A. D. Dudin, and G. G. Smirnov (1986), Venus rock composition at the VEGA 2 landing site, J. Geophys. Res., 91, 215-218.

Surkov, I. A., F. F. Kirnozov, V. N. Glazov, A. G. Dunchenko, and L. P. Tatsy (1987), Uranium, thorium, and potassium in the Venusian rocks at the landing sites of VEGA 1 and 2, J. Geophys. Res., 92, 537-540.

Surkov, Y. A., and V. L. Barsukov (1985), Composition, structure and properties of Venus rocks, Adv. Space Res., 5, 17-29, doi:10.1016/0273-1177(85)90237-6.

Svedhem, H., et al. (2007), Venus Express - The first European mission to Venus, Planet. Space Sci., 55, 1636-1652, doi:10.1016/j.pss.2007.01.013.

Thordarson, T., and G. Larsen (2007), Volcanism in iceland in historical time: Volcano types, eruption styles and eruptive history, J. Geodyn., 43(1), 118-152, doi:10.1016/j.jog.2006.09.005.

Treiman, A. H., and C. C. Allen (1994), Chemical Weathering on Venus: Preliminary Results on the Interaction of Basalt with Carbon Dioxide, vol. 25, pp. 1415-1416.

Turcotte, D. L. (1989), A heat-pipe mechanism for volcanism and tectonics on Venus, J. Geophys. Res., 94, 2779-2785, doi:10.1029/JB094iB03p02779.

Wadge, G. (1981), The variation of magma discharge during basaltic eruptions, J. Volcanol. Geotherm. Res., 11, 139-168, doi:10.1016/0377-0273(81)90020-2.

White, S. M., J. A. Crisp, and F. J. Spera (2006), Long-term volumetric eruption rates and magma budgets, Geochem. Geophys. Geosyst., 7, Q03010, doi:10.1029/2005GC001002.

Wooster, M. J., R. Wright, S. Blake, and D. A. Rothery (1997), Cooling mechanisms and an approximate thermal budget for the $1991-1993$ Mount Etna lava flow, Geophys. Res. Lett., 24, 3277-3280, doi:10.1029/97GL03166.

Wright, R., L. Glaze, and S. M. Baloga (2011), Constraints on determining the eruption style and composition of terrestrial lavas from space, Geology, 39(12), 1127-1130, doi:10.1130/G32341.1. 